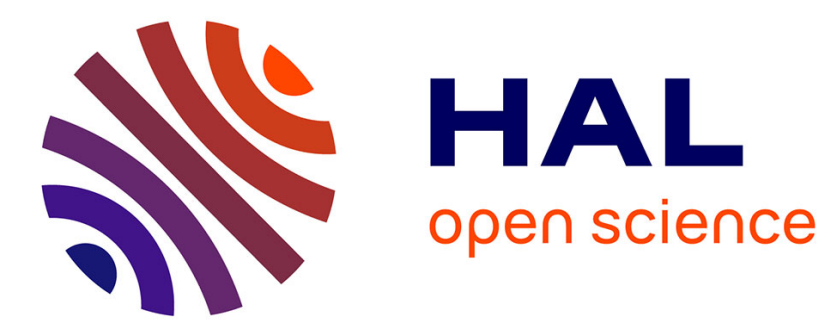

\title{
Mechanisms and kinetics of organic matrix thermal oxidation
}

\author{
Xavier Colin, Jacques Verdu
}

\section{To cite this version:}

Xavier Colin, Jacques Verdu. Mechanisms and kinetics of organic matrix thermal oxidation. LongTerm Durability of Polymeric Matrix Composites, Springer, pp.311-344, 2012, 978-1-4419-9307-6. 10.1007/978-1-4419-9308-3_8. hal-02618533

\section{HAL Id: hal-02618533 \\ https://hal.science/hal-02618533}

Submitted on 25 May 2020

HAL is a multi-disciplinary open access archive for the deposit and dissemination of scientific research documents, whether they are published or not. The documents may come from teaching and research institutions in France or abroad, or from public or private research centers.
L'archive ouverte pluridisciplinaire HAL, est destinée au dépôt et à la diffusion de documents scientifiques de niveau recherche, publiés ou non, émanant des établissements d'enseignement et de recherche français ou étrangers, des laboratoires publics ou privés. 


\title{
Mechanisms and Kinetics of Organic Matrix Thermal Oxidation
}

\author{
Xavier Colin and Jacques Verdu
}

\begin{abstract}
It is now well recognized that during thermal aging at moderate temperatures, for example, typically below the glass transition temperature, organic matrix composites perish mainly by matrix embrittlement resulting from its thermooxidation. The present chapter aims to briefly introduce this domain. The chapter consists of a brief history of polymer oxidation and description of mechanisms and kinetics. The radical character of oxidation processes; the main elementary steps: propagation, termination, initiation processes, and initial steps; structure-property relationships; the nature of oxidation products; and experimental methods for the study of oxidation mechanisms are also discussed. The standard kinetic scheme, case of oxygen excess and general shape of oxidation kinetic curves, the induction period, departure from Arrhenius law, and case of oxygen lack are described. Consequences of oxidation on matrix thermomechanical properties including chain scission and cross-linking physical approaches are presented.
\end{abstract}

\subsection{Introduction}

One can situate the birth date of research in composite thermal aging in the 1960s, as soon as these materials appeared in the market. In the following decades, practically with the beginning of the 1990s, lifetime prediction studies were based on only two experimental tools: gravimetry and mechanical testing, and one theoretical tool: Arrhenius law to extrapolate results obtained during accelerated aging (at high temperature) to use temperature. A first problem, systematically found in the case of thermoset matrices and sometimes in thermoplastic ones, is illustrated by the example of polyester (25\%)-glass fiber $(75 \%)$ composites in the $180-260^{\circ} \mathrm{C}$ temperature range [48]. These authors tried to

\footnotetext{
X. Colin $(\bowtie)$
}

ARTS ET METIERS ParisTech, PIMM, 151 boulevard de l'Hôpital, 75013 Paris, France e-mail: Xavier.COLIN@ensam.eu 


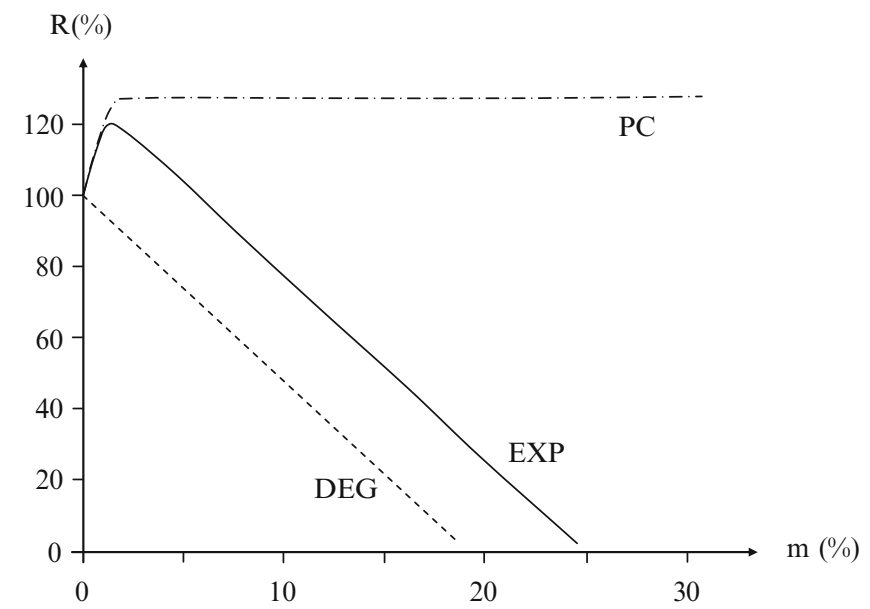

Fig. 8.1 Schematic shape of residual strength-mass loss curve $(E X P)$ and its deconvolution into two components: post-cure $(P C)$ and degradation $(D E G)$

correlate the residual flexural strength $\mathrm{R}$, expressed in percents of the initial value, with the relative weight loss: $\mathrm{m}=\Delta \mathrm{w} / \mathrm{w}_{0}$ (Fig. 8.1).

A linear fit of experimental points gave, approximately,

$$
\mathrm{R} \approx 130-5 \mathrm{~m}
$$

This result calls for the following comments:

- The residual strength varies non-monotonically with mass loss (and time) because its variations result from two opposite processes: post-cure, which tends to increase the mechanical strength, and degradation, which leads always to a strength decrease. Here, post-cure is faster than degradation so that it predominates in a short initial period, after which it stops because all the reactive functions available for cross-linking have been consumed. Then degradation predominates. It is noteworthy that since post-cure and degradation have different activation energies, except for a coincidence, this peculiar behavior can exist only in a more or less restricted temperature interval and disappears far above and far below the temperature range of accelerated aging. Indeed, the amplitude of post-cure effects is expected to sharply depend on cure conditions, especially cure temperature (Fig. 8.2).

$\mathrm{T}_{\mathrm{g}}$ increases continuously with the cure conversion in thermosets [35]. Its (real or virtual) maximum value $\mathrm{T}_{\mathrm{g} \infty}$ corresponds to a full conversion $(\mathrm{y}=1)$. Let us first consider a cure performed at a temperature $\mathrm{T}_{\mathrm{c} 1}<\mathrm{T}_{\mathrm{g} \infty}$. It will be stopped at the sample vitrification $\left(\mathrm{y}=\mathrm{y}_{1}\right)$. Indeed, in further aging at temperature $\mathrm{T}_{\mathrm{a}}>\mathrm{T}_{\mathrm{c} 1}$, the polymer will undergo a post-cure of amplitude $\left(y_{a}-y_{1}\right)$. For a cure at $T_{a}>T_{g \infty}$, the conversion of cure reactions is expected to be complete; no post-cure effect will be observed during further thermal aging. In the case where $\mathrm{T}_{\mathrm{g} \infty}$ is very high, typically above $450-550 \mathrm{~K}$ depending 
Fig. 8.2 Shape of the change of glass transition temperature $\mathrm{T}_{\mathrm{g}}$ with cure conversion ratio y. Full line: Variation of $\mathrm{T}_{\mathrm{g}}$. Dashed line: Degradation temperature $\left(\mathrm{T}_{\mathrm{d}}\right)$

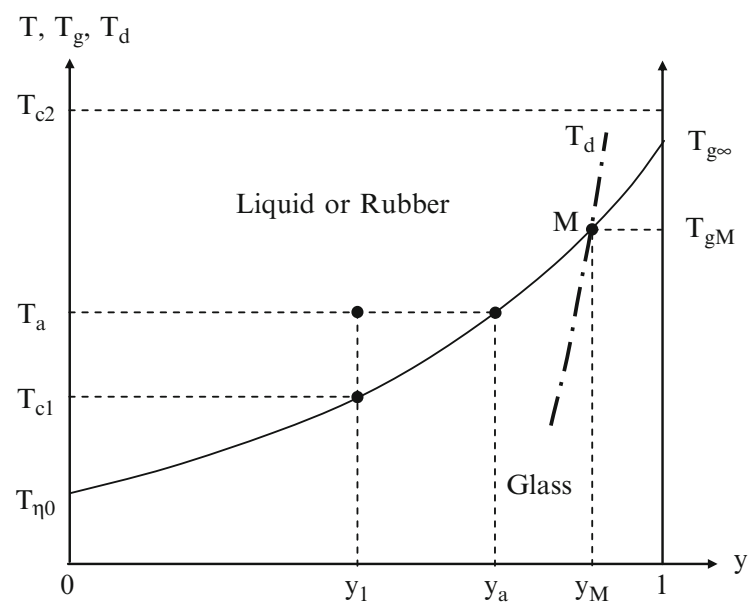

on polymer structure, degradation and/or side reactions occurring in the timescale of cure can limit cross-link density. Using an arbitrary end-life criterion, one can define a "degradation ceiling" surface of which the projection in the plane of Fig. 8.2 crosses the curve $\mathrm{T}_{\mathrm{g}}=\mathrm{f}(\mathrm{y})$ at the point $\mathrm{M}\left(\mathrm{y}_{\mathrm{M}}, \mathrm{T}_{\mathrm{gM}}\right)$. At $\mathrm{T}>\mathrm{T}_{\mathrm{gM}}$, degradation predominates over cure and $\mathrm{T}_{\mathrm{g}}$ decreases. There is no way to obtain $\mathrm{T}_{\mathrm{g}}$ values higher than $\mathrm{T}_{\mathrm{gM}}$. The problem of degradation during processing has raised a great amount of literature in the field of thermostable polymers (polyimides, for instance) and high $\mathrm{T}_{\mathrm{g}}$ epoxies (tetraglycidyl derivative of diaminodiphenylmethane systems, for instance). In all these cases, the presence of oxygen aggravates the problem.

- The strength vanishes only when the matrix is totally volatilized, which indicates a relatively low sensitivity of composite mechanical properties to structural changes occurring in the matrix. There are two possible ways to explain such a behavior: (1) Degradation is homogeneously distributed into the sample volume, the matrix is progressively converted in more and more small (more and more volatile) molecular fragments. In this case, however, mass loss is expected to autoaccelerate catastrophically beyond a certain time, which is not observed here. (2) Degradation occurs in a limited superficial layer which is progressively eroded. Schematically, the residual strength would decrease in proportion to the thickness of the (sound) core layer.

The second "scenario" seems to be more plausible than the first one, but it is only realistic if a diffusion-controlled process explains why the superficial layer degrades preferentially. In 1972, there was sufficient scientific knowledge to identify diffusion-controlled thermal oxidation as the cause of this behavior. Polymer oxidation mechanisms and kinetics were abundantly studied in the preceding quarter of a century, but essentially in the rubber community, and scarce publications were available on the reaction-diffusion coupling [30], but only in the case of hydrolysis. 
Unfortunately, these results remained ignored by the composite community until the turn of the century. Starting from the assumption that composite aging results from the diffusion-controlled oxidation of the matrix, one can hold serious reservations about the use of Arrhenius law to extrapolate accelerated aging data. As a matter of fact, rigorously speaking, Arrhenius law applies only to an elementary process. It can apply also to a complex process if the global rate $r$ of this latter can be expressed as a product of elementary rate constants:

$$
\mathrm{r}=\mathrm{Ak}_{1}^{\mathrm{a}_{1}} \mathrm{k}_{2}^{\mathrm{a}_{2}} \ldots \mathrm{k}_{\mathrm{n}}^{\mathrm{a}_{\mathrm{n}}}
$$

In this case, the apparent activation energy of $r$ is

$$
\mathrm{H}=\mathrm{a}_{1} \mathrm{H}_{1}+\mathrm{a}_{2} \mathrm{H}_{2}+\cdots+\mathrm{a}_{\mathrm{n}} \mathrm{H}_{\mathrm{n}}
$$

where $H_{1}, H_{2}, \ldots H_{n}$ are the activation energies of $k_{1}, k_{2}, \ldots k_{n}$.

Arrhenius law is no longer valid if the global rate is a sum of rate constants:

$$
\mathrm{r}=\mathrm{A}_{1} \mathrm{k}_{1}^{\mathrm{a}_{1}}+\mathrm{A}_{2} \mathrm{k}_{2}^{\mathrm{a}_{2}}+\cdots+\mathrm{A}_{\mathrm{n}} \mathrm{k}_{\mathrm{n}}^{\mathrm{a}_{\mathrm{n}}}
$$

In the case under study, oxidation is a very complex process involving, at least, six elementary reactions. As will be shown in the following, the global oxidation rate does not obey Arrhenius law. However, it is diffusion controlled, oxidation occurs in a superficial layer, and the thickness distribution of oxidation products is temperature dependent. In such a case, the fact that the global change of composite properties obeys Arrhenius law would result from a very surprising coincidence. When such a problem reaches such a degree of complexity, it is tempting to search for an empirical solution. However, empirical approaches, which can be efficient in interpolations, are inadequate for extrapolations as in the case of aging. The only reasonable way is, therefore, the scientific way in which the kinetic scheme is derived from a mechanistic scheme, the latter being established from analytical investigations.

For composites, the first attempts at kinetic modeling (considering diffusioncontrolled oxidation) were made in the 1980s-1990s $[9,10,20,22,33,34,43,44$, 47]. Their common characteristic is that they ignored the work published in the 1940s-1980s on the oxidation of hydrocarbon polymers, including diffusioncontrolled oxidation [21, 27, 45, 49,51], and they used fully empirical kinetic models. A detailed analysis of these works would be out of the scope of this chapter. The model of McManus and colleagues [22] will be quoted just to illustrate this empirical character and the difference with further approaches. These authors proposed the following kinetic expression:

$$
\frac{\partial \mathrm{a}}{\partial \mathrm{t}}=\mathrm{k}(1-\mathrm{a})^{\mathrm{n}} \mathrm{C}^{\mathrm{p}}
$$


where $\mathrm{a}$ is the conversion degree of the whole oxidation process, $\mathrm{C}$ is the oxygen concentration, $\mathrm{k}$ is a rate constant obeying Arrhenius law, $\mathrm{n}$ and $\mathrm{p}$ are apparent reaction orders.

Here, oxidation is practically considered as a single polymer-oxygen reaction but, indeed, the partial order ( $n$ and $p$ ) values would be difficult to justify from mechanistic considerations. They are, in fact, adjustable parameters. At the turn of the century, our research group at Arts et Metiers ParisTech, proposed to build the lifetime prediction approach, around a mechanistic scheme profiting from the advances made by the hydrocarbon polymer oxidation community in the previous half century, trying to consider composite (or matrix) aging as a multiscale problem, and giving to the model an open structure to be progressively complexified, as well in terms of mechanisms as in terms of structure-property relationships.

This chapter is aimed at describing the recent advances in matrix oxidation mechanisms and kinetics. It will be organized into three sections:

1. Mechanisms, in which the main elementary steps will be described, structureproperty relationships will be considered when they are available, and a brief description of most common experimental methods will be made

2. Kinetics, in which standard kinetic schemes, distinguishing the cases of oxygen excess and oxygen lack, will be examined, and where the problem of reactiondiffusion coupling will be briefly treated

3. Consequences of oxidation on matrix physical properties, including mass variations, volumetric properties, glass transition temperature, elastic properties, and fracture properties

\subsection{Mechanisms}

\subsubsection{The Standard Mechanistic Scheme}

The oxidation of organic substrates results from a radical chain mechanism established for the first time by Semenov (Nobel Prize 1956) in the 1930s [46]. In the polymer community of Western countries, however, this mechanism remained ignored until the end of World War II where it was rediscovered by a British team [8], often considered the founder of the discipline. A radical chain process involves at least three steps:

\begin{tabular}{lll}
\hline Initiation & Non-radical species & $\rightarrow$ Radicals \\
Propagation & One radical & $\rightarrow$ One radical \\
Initiation & Two radicals & $\rightarrow$ Non-radical species \\
\hline
\end{tabular}


The following nomenclature will be used here: $\mathrm{P}^{\circ}$ : alkyl radical (although the existence of aryl radicals is not excluded); $\mathrm{PO}_{2}{ }^{\circ}$ : peroxy radical (or peroxyl); POOH: hydroperoxide; PH: the substrate.

In the case of radical chain oxidation, the propagation involves two elementary reactions and two radicals: $\mathrm{P}^{\circ}$ and $\mathrm{PO}_{2}^{\circ}$. In a saturated substrate:

\begin{tabular}{llll}
\hline (II) & $\mathrm{P}^{\circ}+\mathrm{O}_{2}$ & $\rightarrow \mathrm{PO}_{2}^{\circ}$ & $\left(\mathrm{k}_{2}\right)$ \\
(III) & $\mathrm{PO}_{2}^{\circ}+\mathrm{PH}$ & $\rightarrow \mathrm{POOH}+\mathrm{P}^{\circ}$ & $\left(\mathrm{k}_{3}\right)$ \\
\hline
\end{tabular}

In an unsaturated substrate, the previous mechanism can coexist with the addition of $\mathrm{PO}_{2}{ }^{\circ}$ to double bonds:

\begin{tabular}{|c|c|c|c|}
\hline (IIIa) & $\mathrm{PO}_{2}^{\circ}+\stackrel{\mathrm{C}}{\mathrm{C}}=\mathrm{C}$ & $\rightarrow \mathrm{P}-\mathrm{O}-\mathrm{O}-\stackrel{\mathrm{I}}{\mathrm{C}}-{ }_{\mathrm{I}}^{\mathrm{I}} \mathrm{C}^{\circ}$ & $\left(\mathrm{k}_{3 \mathrm{a}}\right)$ \\
\hline
\end{tabular}

This latter reaction can be important in unsaturated polymers such as polydienes $[17,19]$, but it will not be considered here, because unsaturations are scarce in common composite matrices.

In terminations, radicals deactivate mutually in pairs:

\begin{tabular}{llll}
\hline IV) & $\mathrm{P}^{\circ}+\mathrm{P}^{\circ}$ & $\rightarrow$ Inactive species & $\left(\mathrm{k}_{4}\right)$ \\
$(\mathrm{V})$ & $\mathrm{P}^{\circ}+\mathrm{PO}_{2}^{\circ}$ & $\rightarrow$ Inactive species & $\left(\mathrm{k}_{5}\right)$ \\
$(\mathrm{VI})$ & $\mathrm{PO}_{2}^{\circ}+\mathrm{PO}_{2}^{\circ}$ & $\rightarrow$ Inactive species $+\mathrm{O}_{2}$ & $\left(\mathrm{k}_{6}\right)$ \\
\hline
\end{tabular}

All these terminations can result from radical coupling:

\begin{tabular}{ll}
\hline $\mathrm{P}^{\circ}+\mathrm{P}^{\circ}$ & $\rightarrow \mathrm{P}-\mathrm{P}$ \\
$\mathrm{P}^{\circ}+\mathrm{PO}_{2}^{\circ}$ & $\rightarrow \mathrm{P}-\mathrm{O}-\mathrm{O}-\mathrm{P}$ \\
$\mathrm{PO}_{2}^{\circ}+\mathrm{PO}_{2}^{\circ}$ & $\rightarrow \mathrm{P}-\mathrm{O}-\mathrm{O}-\mathrm{O}-\mathrm{O}-\mathrm{P}$ (very unstable) $\quad \rightarrow \mathrm{P}-\mathrm{O}-\mathrm{O}-\mathrm{P}+\mathrm{O}_{2}$ \\
\hline
\end{tabular}

If, at least, one radical contains one hydrogen in $\beta$ position, termination can also result from a disproportionation:

$$
\begin{aligned}
& \mathrm{P}^{\circ}+\stackrel{\stackrel{\circ}{\mathrm{C}}-\mathrm{CH}_{\perp}^{\prime}}{\rightarrow} \mathrm{PH}+{ }_{I}^{\prime}{ }_{\mathrm{C}}=\mathrm{C}_{\perp}^{\prime}
\end{aligned}
$$

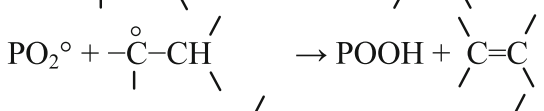

$$
\begin{aligned}
& \mathrm{P}-\mathrm{O}-\mathrm{O}-\mathrm{O}-\mathrm{O}-\mathrm{CH}_{\backslash}^{\prime} \rightarrow\left[\mathrm{PO}^{\circ}{ }^{\circ} \mathrm{O}-\mathrm{CH}^{\prime}\right]_{\text {cage }}+\mathrm{O}_{2} \\
& \rightarrow \mathrm{P}-\mathrm{OH}+\mathrm{O}=\stackrel{\text { C }}{\prime}
\end{aligned}
$$

Coupling and disproportionation can coexist.

Three initiation mechanisms can exist, in the absence of any extrinsic initiating agent (irradiation, presence of a radical initiator, etc.). 
Fig. 8.4 Shape of the pressure dependence of the maximum oxidation rate: (1) reaction $\left(\mathrm{I}^{\prime \prime}\right)$ negligible; $(2)$ significant contribution of reaction $\left(\mathrm{I}^{\prime \prime}\right)$ to initiation

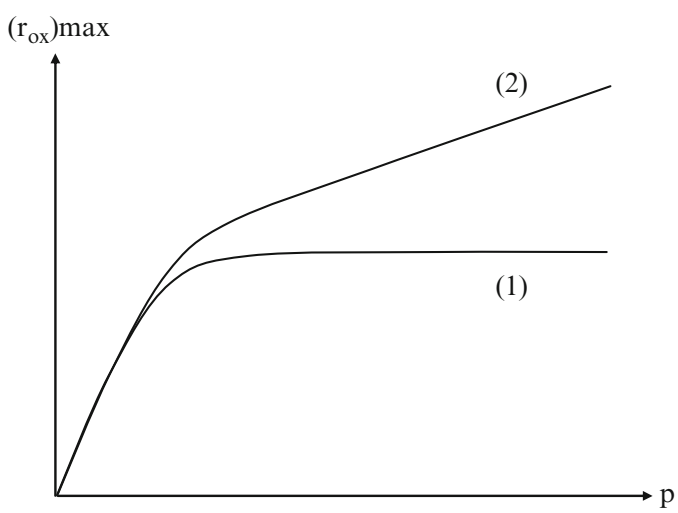

slowly as the result of substrate consumption. In certain cases, however, when samples are pre-oxidized during processing, or at relatively high temperatures where hydroperoxide decomposition is very fast, the autoaccelerated character can disappear while initiation by $\mathrm{POOH}$ decomposition predominates. In such cases, the relative importance of reactions $\left(\mathrm{I}^{\prime \prime}\right)$ and $\left(\mathrm{I}^{\prime}\right)$ can be recognized from the effect of oxygen pressure on maximum oxidation rate (Fig. 8.4).

Let us consider the theoretical case of a substrate initially free of hydroperoxides. In this case, if oxidation occurs, it is necessarily due to the existence of a process of radical generation other than hydroperoxide decomposition. For a long time, the question of the nature of these initial steps has been considered crucial by the community, and some confusion appeared between "initial steps" and "initiation steps." In general, the nature of eventual "initial steps" is impossible to establish because the corresponding reactive species are in concentrations too low to be measurable. Kinetic modeling brings some light on this almost metaphysical problem: the radicals produced in initial steps are transformed into hydroperoxides of which the concentration increases in such a way as hydroperoxide decomposition becomes rapidly the predominating initiation process, which fully determines the autoaccelerated behavior and, eventually, the length of the induction period [39].

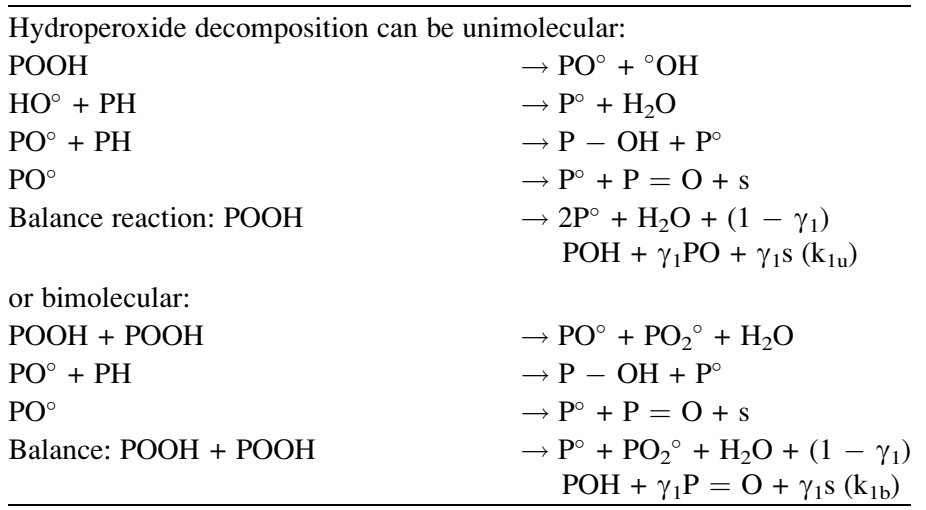


Since $\mathrm{HO}^{\circ}$ and $\mathrm{PO}^{\circ}$ radicals are extremely reactive (they cannot be observed by electron spin resonance (ESR)), the rate-controlling step is the hydroperoxide decomposition and it is licit to consider the balance reaction as a virtual single elementary step.

$\mathrm{PO}^{\circ}$ radicals can react by hydrogen abstraction to give an alcohol or by rearrangement ( $\beta$ scission):

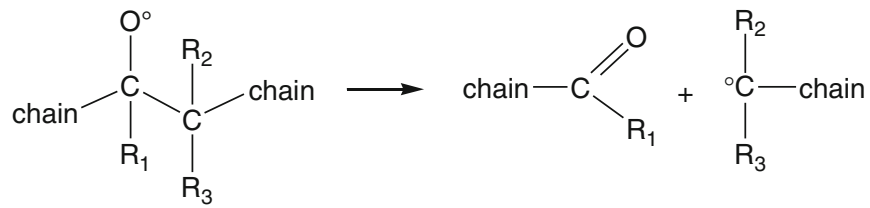

This reaction gives a carbonyl group $\mathrm{P}=\mathrm{O}$ (absorbing in the $1650-1850 \mathrm{~cm}^{-1}$ spectral IR range with a relatively high molar absorptivity: $\varepsilon \approx 150-600 \mathrm{~L}$ $\mathrm{mol}^{-1} \mathrm{~cm}^{-1}$ ) and a chain scission (s). As will be seen, chain scissions play a key role in mechanical property changes.

Let us consider the rates of radical production by both mechanisms:

\begin{tabular}{ll}
\hline Unimolecular & $\mathrm{r}_{1 \mathrm{u}}=2 \mathrm{k}_{1 \mathrm{u}}[\mathrm{POOH}]$ \\
Bimolecular & $\mathrm{r}_{1 \mathrm{~b}}=2 \mathrm{k}_{1 \mathrm{~b}}[\mathrm{POOH}]^{2}$ \\
\hline
\end{tabular}

Both rates are equal when:

$$
[\mathrm{POOH}]=[\mathrm{POOH}]_{\mathrm{C}}=\mathrm{k}_{1 \mathrm{u}} / \mathrm{k}_{1 \mathrm{~b}}
$$

At low $\mathrm{POOH}$ concentration, the unimolecular decomposition predominates, whereas at high $\mathrm{POOH}$ concentration, the bimolecular decomposition predominates. The activation energy of $\mathrm{k}_{1 \mathrm{u}}: \mathrm{E}_{1 \mathrm{u}} \approx 140 \mathrm{~kJ} \mathrm{~mol}^{-1}$ is higher than the activation energy of $\mathrm{k}_{1 \mathrm{~b}}: \mathrm{E}_{1 \mathrm{~b}}=80-120 \mathrm{~kJ} \mathrm{~mol}^{-1}$. Thus, $[\mathrm{POOH}]_{\mathrm{C}}$ is an increasing function of temperature.

To resume: Unimolecular decomposition tends to predominate at high temperature, when hydroperoxides are intrinsically unstable, and when they are in low concentration. Bimolecular decomposition tends to predominate at low temperature, when hydroperoxides are relatively stable, and when they are in relatively high concentration. Indeed, an oxidation process can begin with unimolecular initiation and turn into a bimolecular one when the hydroperoxide concentration becomes higher than the critical one $[\mathrm{POOH}]_{\mathrm{C}}$.

\subsubsection{Structure-Reactivity Relationships}

Even in the most widely studied polymer families, for example, polyolefins and polydienic elastomers, we are far from a consensus about elementary rate constant values. For polymers in glassy state, with heteroatoms and aromatic 
cycles in the chain, fundamental data are almost nonexistent. In other words, oxidation kinetics in composite matrices is an almost virgin research domain. The knowledge about elementary rate constant values can be summarized as follows.

\subsubsection{Relative Orders of Magnitude}

Let us consider, for instance, the $150-200^{\circ} \mathrm{C}$ temperature range. Most common rate constant values would generally be in the following intervals:

$10^{-7} \leq \mathrm{k}_{1 \mathrm{u}} \leq 10^{-3} \mathrm{~s}^{-1}$

$10^{7} \leq \mathrm{k}_{2} \leq 10^{9} \mathrm{~L} \mathrm{~mol}^{-1} \mathrm{~s}^{-1}$

$1 \leq \mathrm{k}_{3} \leq 10^{2} \mathrm{~L} \mathrm{~mol}^{-1} \mathrm{~s}^{-1}$

$10^{\overline{6}} \leq \mathrm{k}_{4}, \mathrm{k}_{5}$ and $\mathrm{k}_{6} \leq 10^{12} \mathrm{~L} \mathrm{~mol}^{-1} \mathrm{~s}^{-1}$

Initiation is, by far, the slowest process. This is the reason why the hydroperoxide accumulation kinetics determines mainly the process autoacceleration.

$\mathrm{k}_{2} \gg \mathrm{k}_{3}$, so that when oxygen is in excess, the hydrogen abstraction process (III) is the propagation rate-controlling process (but not the whole oxidation rate-controlling process as frequently claimed). Furthermore, since $\mathrm{P}^{\circ}$ radicals are very quickly transformed into $\mathrm{PO}_{2}{ }^{\circ}$ ones, their probability of reacting by other ways (terminations (IV) and (V)) becomes negligible, chain termination occurs only by reaction (VI), and the whole reaction rate (in steady state) is sharply linked to the ratio $\mathrm{k}_{3}{ }^{2} / \mathrm{k}_{6}$ [5]. When oxygen is not in excess, the oxidation rate becomes dependent on the oxygen concentration, and this dependence is sharply linked to the value of a composite rate constant $\beta[12,14]$ :

$$
\beta=\frac{\mathrm{k}_{2} \mathrm{k}_{6}}{2 \mathrm{k}_{5} \mathrm{k}_{3}[\mathrm{PH}]}
$$

Schematically, oxygen is in excess when its concentration $\mathrm{C}$ exceeds a critical value $\mathrm{C}_{\mathrm{C}}$ defined by:

$$
\mathrm{C}_{\mathrm{C}}=\mathrm{q} \beta^{-1}
$$

where $\mathrm{q}$ is of the order of 10 .

$\beta$ was found close to $160 \mathrm{~L} \mathrm{~mol}^{-1}$ at $200^{\circ} \mathrm{C}$, as well in an epoxy network as in a poly(bismaleimide) $[12,14]$.

\subsubsection{Rate Constants}

Compilations of rate constant values exist in reference books [23, 38, 50], but they are too parceled or too scattered to permit a coherent synthesis, except, eventually, for the propagation rate constant $\mathrm{k}_{3}$ [31]. According to these authors, 
the rate constant $\mathrm{k}_{3}$ at $30^{\circ} \mathrm{C}$ would be linked to the dissociation energy $\mathrm{E}_{\mathrm{D}}$ of the broken $\mathrm{CH}$ bond by:

$$
\log \mathrm{k}_{3}=\mathrm{A}-0.048 \mathrm{E}_{\mathrm{D}}
$$

where $\mathrm{A}=15.4$ for a tertiary peroxyl and 16.4 for a secondary peroxyl, $\mathrm{k}_{3}$ is expressed in $\mathrm{L} \mathrm{mol}^{-1} \mathrm{~s}^{-1}$ and $\mathrm{E}_{\mathrm{D}}$ in $\mathrm{kJ} \mathrm{mol}^{-1}$.

In a similar way, the activation energy $\mathrm{E}_{3}$ of $\mathrm{k}_{3}$ would be given by:

$$
\mathrm{E}_{3}=0.13\left(\mathrm{E}_{\mathrm{D}}-261\right)
$$

It can be recalled that $\mathrm{E}_{\mathrm{D}}(\mathrm{C}-\mathrm{H})$ ranges from a value close to $500 \mathrm{~kJ} \mathrm{~mol}^{-1}$ (for a $\mathrm{CH}$ in an aromatic ring) to a value of $300-350 \mathrm{~kJ} \mathrm{~mol}^{-1}$ (for a $\mathrm{CH}$ in allylic position, in a benzylic position or in the vicinity of an electronegative atom: $-\mathrm{O}-$ or $-\mathrm{N}<) . \mathrm{k}_{3}\left(30^{\circ} \mathrm{C}\right)$ can thus range between $10^{-4}-10^{-3} \mathrm{~L} \mathrm{~mol}^{-1} \mathrm{~s}^{-1}$ for the most stable aromatic structures, to $0.1-1.0 \mathrm{~L} \mathrm{~mol}^{-1} \mathrm{~s}^{-1}$ for the most unstable (common) structures present in polymers.

Surprisingly, the hierarchy of polymer stabilities to oxidation is roughly correlated to the hierarchy of $\mathrm{E}_{\mathrm{D}}$ values: Polymers having only stable $\mathrm{CH}$ bonds, for example, only aromatic groups and methyls such as polyethersulphone, poly(dimethyl siloxane), various aromatic polyimides, etc., are very stable to oxidation. Polymers having very unstable $\mathrm{CH}$ bonds, for instance, polybutadiene, polyisoprene, polyamides, polyethers, etc., are especially unstable to oxidation. Polyethylene, in which $\mathrm{E}_{\mathrm{D}}$ is intermediary $\left(\mathrm{E}_{\mathrm{D}} \approx 390 \mathrm{~kJ} \mathrm{~mol}^{-1}\right)$, displays a medium stability. The existence of this correlation, indicating the key role of $\mathrm{k}_{3}$, seems to indicate that the other rate constants, especially $\mathrm{k}_{1}$ and $\mathrm{k}_{6}$, which are expected to play a role of the same importance as $\mathrm{k}_{3}$, do not vary much from one polymer to another.

\subsubsection{How to Establish Oxidation Mechanisms}

For pure molecular substances in liquid or gaseous state, it is possible to build a systematic strategy for the elaboration of an oxidation mechanistic scheme. In such a case, oxidation products can be separated and identified by very powerful methods, especially mass spectrometry (MS) and nuclear magnetic resonance (NMR). For polymers, especially thermosets, this separation is very difficult or even impossible. Furthermore, NMR lacks of sensitivity in the conversion range of practical interest. In conditions of thermal oxidation, electron spin resonance (ESR), which is the tool for radical identification, also lacks of sensitivity owing to the very low steady concentration of radicals (especially $\mathrm{P}^{\circ}$ ones). The remaining available methods are scarce: Infrared spectrophotometry (IR), hydroperoxide chemical titration, and elementary analysis give generally useful information, but these can lead only to a fuzzy image of the structural changes undergone by the polymer. 
The most common way to establish oxidation mechanisms cannot be, finally, depicted as a linear, fully logical reasoning. It consists of starting from the assumption that oxidation obeys the standard mechanistic scheme which displays the following characteristics:

1. Hydroperoxides are the unique propagation products

2. Initiation results only from hydroperoxide decomposition

3. All the other products result from initiation, termination, or side reactions

Three important quantitative data are eventually accessible: The whole quantity of oxygen reacted with the polymer (from manometric measurements in a closed cell during exposure or from elementary analysis); the hydroperoxide concentration; and the nature of predominating carbonyl groups (IR). By cross-checking this information with kinetic data (see below), it must be possible to validate the starting assumptions of mechanism or to choose another one. When ambiguities remain, for instance, about the nature of reactive sites and their relative importance, the recourse to studies of model compounds, to which the analytical methods of organic chemistry are fully applicable, can be useful.

\subsection{Kinetics}

Let us consider the standard mechanistic scheme:

\begin{tabular}{llr}
\hline$\delta \mathrm{POOH}$ & $\rightarrow \alpha \mathrm{P}^{\circ}+\beta_{\mathrm{PO}_{2}}^{\circ}$ & $\left(\mathrm{k}_{1}\right)$ \\
$\mathrm{P}^{\circ}+\mathrm{O}_{2}$ & $\rightarrow \mathrm{PO}_{2}^{\circ}$ & $\left(\mathrm{k}_{2}\right)$ \\
$\mathrm{PO}_{2}^{\circ}+\mathrm{PH}$ & $\rightarrow \mathrm{POOH}+\mathrm{P}^{\circ}$ & $\left(\mathrm{k}_{3}\right)$ \\
$\mathrm{P}^{\circ}+\mathrm{P}^{\circ}$ & $\rightarrow$ Inactive species & $\left(\mathrm{k}_{4}\right)$ \\
$\mathrm{P}^{\circ}+\mathrm{PO}_{2}^{\circ}$ & $\rightarrow$ Inactive species & $\left(\mathrm{k}_{5}\right)$ \\
$\mathrm{PO}_{2}^{\circ}+\mathrm{PO}_{2}^{\circ}$ & $\rightarrow$ Inactive species $+\mathrm{O}_{2}$ & $\left(\mathrm{k}_{6}\right)$ \\
\hline
\end{tabular}

The following basic principles of chemical kinetics can be applied if oxidation can be considered homogeneous, for example, when the concentrations have a physical sense, which leads to considering local concentrations (in thin thickness layers):

- Concentrations are generally expressed in moles per liter $\left(\mathrm{mol} \mathrm{L}^{-1}\right)$.

- In an elementary step, reaction rates are always expressed as functions of reactants (left side of the arrow). Except in very scarce cases, reaction rates are proportional to reactant concentrations.

- For the whole process, the variation rate of a given species concentration is the algebraic sum of the elementary rates.

Application of these principles to the above scheme leads to the following set of differential equations: 


$$
\begin{aligned}
\frac{\mathrm{d}\left[\mathrm{P}^{\circ}\right]}{\mathrm{dt}}= & \alpha \mathrm{k}_{1}[\mathrm{POOH}]^{\delta}-\mathrm{k}_{2}\left[\mathrm{O}_{2}\right]\left[\mathrm{P}^{\circ}\right]+\mathrm{k}_{3}[\mathrm{PH}]\left[\mathrm{PO}_{2}^{\circ}\right]-2 \mathrm{k}_{4}\left[\mathrm{P}^{\circ}\right]^{2} \\
& -\mathrm{k}_{5}\left[\mathrm{P}^{\circ}\right]\left[\mathrm{PO}_{2}^{\circ}\right] \\
\frac{\mathrm{d}\left[\mathrm{PO}_{2}^{\circ}\right]}{\mathrm{dt}=} & \beta \mathrm{k}_{1}[\mathrm{POOH}]^{\delta}+\mathrm{k}_{2}\left[\mathrm{O}_{2}\right]\left[\mathrm{P}^{\circ}\right]-\mathrm{k}_{3}[\mathrm{PH}]\left[\mathrm{PO}_{2}^{\circ}\right]-\mathrm{k}_{5}\left[\mathrm{P}^{\circ}\right]\left[\mathrm{PO}_{2}^{\circ}\right] \\
& -2 \mathrm{k}_{6}\left[\mathrm{PO}_{2}^{\circ}\right]^{2} \\
\frac{\mathrm{d}[\mathrm{POOH}]}{\mathrm{dt}}= & \mathrm{k}_{3}[\mathrm{PH}]\left[\mathrm{PO}_{2}^{\circ}\right]-\delta \mathrm{k}_{1}[\mathrm{POOH}]^{\delta} \\
\frac{\mathrm{d}[\mathrm{PH}]}{\mathrm{dt}}= & -\mathrm{k}_{3}[\mathrm{PH}]\left[\mathrm{PO}_{2}^{\circ}\right]-\gamma \mathrm{k}_{1}[\mathrm{POOH}]^{\delta} \\
\frac{\mathrm{d}\left[\mathrm{O}_{2}\right]}{\mathrm{dt}}= & -\mathrm{k}_{2}\left[\mathrm{O}_{2}\right]\left[\mathrm{P}^{\circ}\right]+\mathrm{k}_{6}\left[\mathrm{PO}_{2}^{\circ}\right]^{2}+\mathrm{Diff}
\end{aligned}
$$

Boundary conditions are:

- At $\mathrm{t}=0:\left[\mathrm{P}^{\circ}\right]=\left[\mathrm{PO}_{2}^{\circ}\right]=0 ;[\mathrm{POOH}]=[\mathrm{POOH}]_{0} ;[\mathrm{PH}]=[\mathrm{PH}]_{0}$

- At every time: $\left[\mathrm{O}_{2}\right]=\left[\mathrm{O}_{2}\right]_{\mathrm{S}}$ (equilibrium oxygen concentration) in the sample superficial layer. $\left[\mathrm{O}_{2}\right]_{\mathrm{S}}=\mathrm{Sp}$, where $\mathrm{p}$ is the oxygen pressure and $\mathrm{S}$ is the oxygen solubility in the polymer

$\gamma$ is the number of $\mathrm{PH}$ groups consumed in one hydroperoxide decomposition event (generally $1<\gamma<2$ ).

"Diff" is a term expressing oxygen supply by diffusion (see below).

In classical approaches, several simplifying assumptions are made:

1. Low conversions. Since, often, embrittlement occurs at low conversions, it is licit to consider that substrate consumption is negligible and, thus, that $[\mathrm{PH}]$ $=[\mathrm{PH}]_{0}=$ constant. However, in this case, there is no way to simulate the final autoretardation process, which is generally observed in kinetic curves (Fig. 8.5).

2. Constant oxygen concentration: $\left[\mathrm{O}_{2}\right]=\left[\mathrm{O}_{2}\right]_{\mathrm{S}}$. This assumption is only valid in thin films or in a thin superficial layer of thick samples. In this case: Diff $=0$.

3. Oxygen excess (only possible in thin samples and superficial layers). In this case, the terms $\mathrm{k}_{4}\left[\mathrm{P}^{\circ}\right]^{2}$ and $\mathrm{k}_{5}\left[\mathrm{P}^{\circ}\right]\left[\mathrm{PO}_{2}^{\circ}\right]$ vanish.

Analytical models exist in this case (using assumption (1) and the assumptions that there is a steady state for whole radical concentration: $d\left[\mathrm{P}^{\circ}\right] / d t+d\left[\mathrm{PO}_{2}{ }^{\circ}\right] /$ $\mathrm{dt}=0$, and that a steady state is reached when $\mathrm{d}[\mathrm{POOH}] / \mathrm{dt}=0)$. Two distinct models have been elaborated for unimolecular and bimolecular hydroperoxide decomposition by Tobolsky et al. [51]. They were almost totally ignored or forgotten by the community until the middle of 1990s [4]. Their properties were studied in detail [5], and small improvements were proposed [16]. 
$\mathrm{Q}_{\mathrm{ox}}$

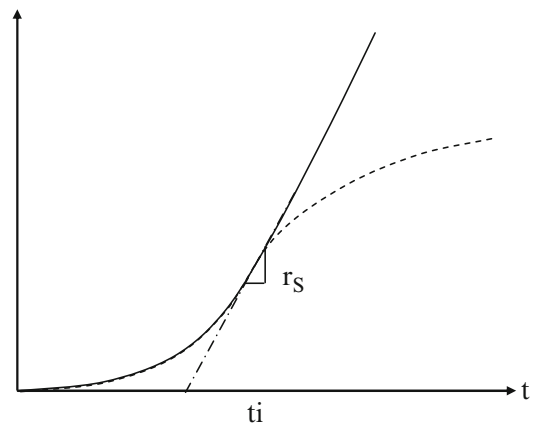

$\mathrm{r}_{\mathrm{ox}},[\mathrm{POOH}]$

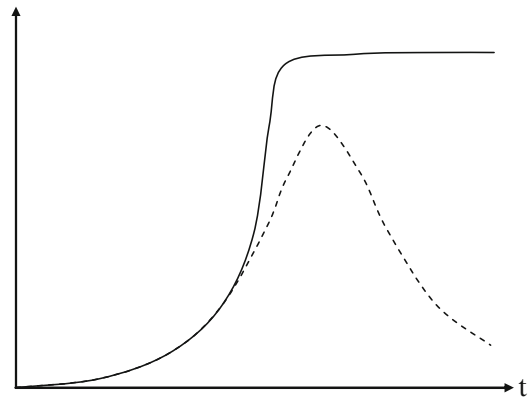

Fig. 8.5 Kinetic curves. Left: Oxygen consumption or stable products accumulation (for instance, carbonyls). Right: Oxidation rate or $\mathrm{POOH}$ formation. Full line: Model with $[\mathrm{PH}]=[\mathrm{PH}]_{0}=$ constant. Dashed line: Experimental curve
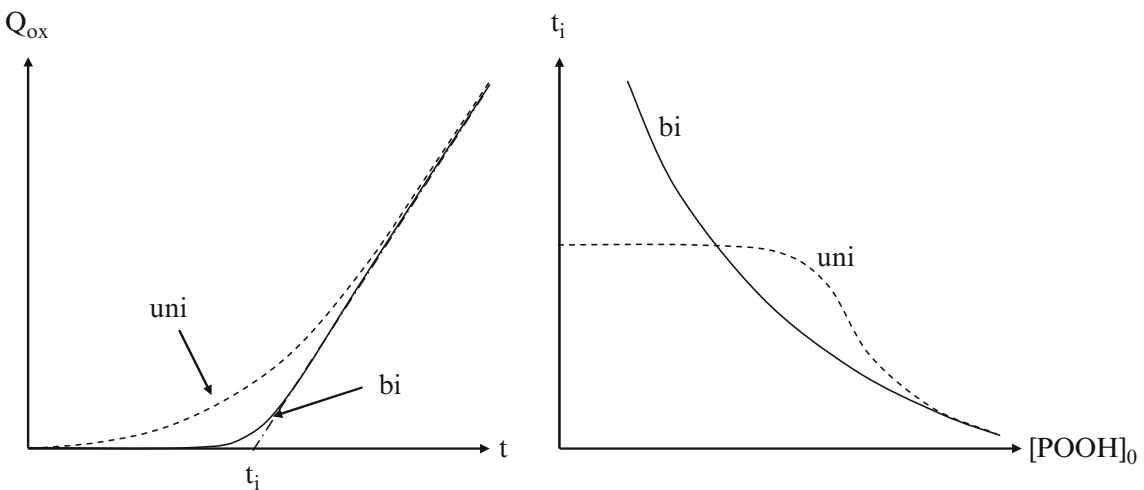

Fig. 8.6 Left: Shape of oxidation kinetic curves for unimolecular (uni) and bimolecular (bi) $\mathrm{POOH}$ decomposition. Right: Variation of the induction time with the initial hydroperoxide concentration for unimolecular (uni) and bimolecular (bi) $\mathrm{POOH}$ decomposition

Despite their simplicity, these models are very useful in appreciating the trends of kinetic behavior with the exposure parameters and rate constant values or structural variables. Unimolecular and bimolecular hydroperoxide decomposition display two important differences (Fig. 8.6).

Autoacceleration during the induction period is more progressive for unimolecular than for bimolecular decomposition. At low initial POOH decomposition, the induction time tends to be independent of $[\mathrm{POOH}]_{0}$ for low $[\mathrm{POOH}]_{0}$ values in the case of unimolecular decomposition, whereas it increases continuously, when $[\mathrm{POOH}]_{0}$ decreases, in the case of bimolecular decomposition. Indeed, since both 
initiation modes are competitive, unimolecular decomposition predominates at low $[\mathrm{POOH}]_{0}$ values, whereas bimolecular decomposition predominates at high $[\mathrm{POOH}]_{0}$ values. The best way for modeling consists, thus, in taking into account, simultaneously, both initiation modes, but in this case, we have to renounce to analytical solutions. Analytical expressions of the induction time are very simple [5]. For unimolecular initiation, at low $[\mathrm{POOH}]_{0}$ :

$$
\mathrm{t}_{\mathrm{i}}=\frac{\mathrm{A}}{\mathrm{k}_{1 \mathrm{u}}}
$$

where $\mathrm{A}=2.5$ or 3.0 , depending on the chosen criterion.

For bimolecular initiation:

$$
\mathrm{t}_{\mathrm{i}}=\frac{\operatorname{Ln} \mathrm{b}}{\mathrm{K}}
$$

where:

$$
\mathrm{b}=\frac{[\mathrm{POOH}]_{\infty}}{[\mathrm{POOH}]_{0}} ; \quad[\mathrm{POOH}]_{\infty}=\frac{\mathrm{k}_{3}[\mathrm{PH}]}{2\left(\mathrm{k}_{1 \mathrm{~b}} \mathrm{k}_{6}\right)^{1 / 2}} ; \quad \text { and } \quad \mathrm{K}=\mathrm{k}_{3}[\mathrm{PH}]\left(\frac{\mathrm{k}_{1 \mathrm{~b}}}{\mathrm{k}_{6}}\right)^{1 / 2}
$$

A general property of these "closed-loop" schemes, where the reaction generates its own initiator, is that the kinetic chain length: $\mathrm{KCL}=$ propagation rate/initiation rate, decreases continuously during the induction period to reach unity in steady state. As a consequence, the apparent activation energy decreases continuously during the induction period. Application of Arrhenius law to predict lifetime appears, therefore, questionable. Since, whatever the initiation mode, the induction time is a decreasing function of temperature, there is a critical temperature above which the induction period vanishes totally. This temperature is as low as initiation is fast and initial hydroperoxide concentration is high.

\subsubsection{Case of Oxygen Lack}

Let us consider now the case of oxygen lack, first in a thin layer (no thickness gradient). The terms $\mathrm{k}_{4}\left[\mathrm{P}^{\circ}\right]^{2}$ and $\mathrm{k}_{5}\left[\mathrm{P}^{\circ}\right]\left[\mathrm{PO}_{2}^{\circ}\right]$ must be reintroduced in the kinetic scheme. Classically, the set of differential equations was solved making the following assumptions:

I : Initiation rate constant $\left(\mathrm{r}_{\mathrm{i}}\right)$, for example, stable hydroperoxides

S: Steady state for the (whole) radical concentration

$\mathrm{T}$ : Relationship between termination rate constants: $\mathrm{k}_{5}^{2}=4 \mathrm{k}_{4} \mathrm{k}_{6}$

L: Long kinetic chain: $\mathrm{k}_{3}[\mathrm{PH}] /\left(2 \mathrm{r}_{\mathrm{i}} \mathrm{k}_{6}\right)^{1 / 2} \gg 1$ 
Fig. 8.7 Shape of the curve: oxygen consumption rate versus oxygen concentration: $\mathrm{r}_{\mathrm{S}}=\mathrm{k}_{3}[\mathrm{PH}]\left(\mathrm{r}_{\mathrm{i}} / 2 \mathrm{k}_{6}\right)^{1 / 2}$

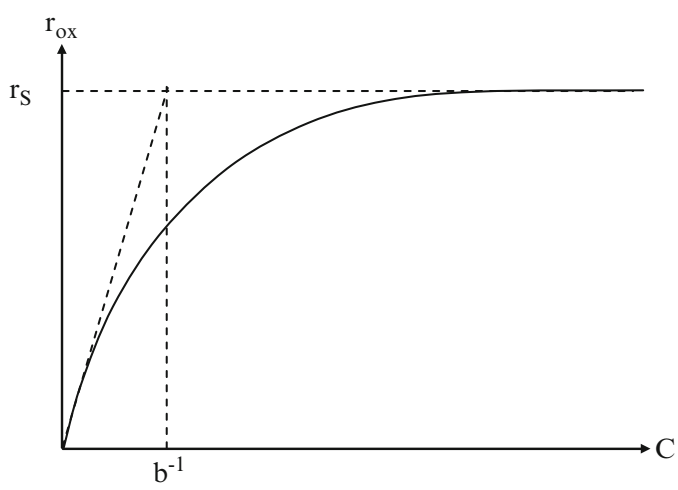

In the frame of this set of assumptions, the oxygen consumption rate $r_{\mathrm{ox}}$ is given by a hyperbolic function [21]:

$$
\mathrm{r}_{\mathrm{oxi}}=\frac{\mathrm{aC}}{1+\mathrm{bC}}
$$

where $\mathrm{C}$ is the oxygen concentration, $\mathrm{a}=\mathrm{k}_{2}\left(\frac{\mathrm{r}_{\mathrm{i}}}{2 \mathrm{k}_{4}}\right)^{1 / 2}$ and $\mathrm{b}=\frac{\mathrm{k}_{2}}{\mathrm{k}_{3}[\mathrm{PH}]}\left(\frac{\mathrm{k}_{6}}{\mathrm{k}_{4}}\right)^{1 / 2}$.

The shape of the curve $r_{\text {ox }}=f(C)$ is shown in Fig. 8.7.

The above set of assumptions is, however, questionable in the case of thermal oxidation where hydroperoxides decompose. Achimsky et al. [2] reconsidered assumption T. For radical mobility reasons [29], it is better to take: $\mathrm{k}_{5}^{2}>4 \mathrm{k}_{4} \mathrm{k}_{6}$, which leads to a new expression of oxygen consumption rate (in the case of unimolecular initiation):

$$
\mathrm{r}_{\mathrm{ox}}=2 \frac{\mathrm{k}_{3}^{2}[\mathrm{PH}]^{2}}{\mathrm{k}_{6}} \frac{\beta \mathrm{C}}{1+\beta \mathrm{C}}\left[1-\frac{\beta \mathrm{C}}{2(1+\beta \mathrm{C})}\right]
$$

where:

$$
\beta=\frac{\mathrm{k}_{2} \mathrm{k}_{6}}{2 \mathrm{k}_{5} \mathrm{k}_{3}[\mathrm{PH}]}
$$

The shape of the curve is the same as Fig. 8.7, but the asymptotic value of $\mathrm{r}_{\mathrm{ox}}: \mathrm{r}_{\mathrm{S}}=\mathrm{k}_{3}{ }^{2}[\mathrm{PH}]^{2} / \mathrm{k}_{6}$, is different. This model was immediately applied to composite matrices [11]. Despite its improvement, this model remains perfectible because it keeps the assumption of steady state, which is questionable. The next step consists in also suppressing this assumption that imposes solving numerically the system of differential equations constituting the kinetic scheme. This type of resolution was performed, for the first time, in the case of photo-oxidation by Sommersall and Guillet [49], but this tentative remained isolated until the turn 
of the century where our research group at Arts et Metiers ParisTech, proposed a numerical approach for the thermo-oxidation kinetics of polypropylene [40], polydiene elastomers [41], or poly(bismaleimides) [13]. The great advantage of the numerical approach is that it permits studying the case of variable initiation rate and, thus, having a better simulation of the autoaccelerated phase of oxidation, during the induction period.

\subsubsection{Diffusion-Controlled Oxidation}

Let us now consider the case of thick samples. Since oxygen is consumed by oxidation, its concentration must be a decreasing function of the layer depth $\mathrm{z}$ in the sample thickness. Then a diffusion term must be included in the oxygen balance equation:

$$
\frac{\partial\left[\mathrm{O}_{2}\right]}{\partial \mathrm{t}}=\mathrm{D} \operatorname{div}\left(\overrightarrow{\operatorname{grad}}\left(\left[\mathrm{O}_{2}\right]\right)\right)-\mathrm{r}_{\mathrm{ox}}\left(\left[\mathrm{O}_{2}\right]\right)
$$

where $\mathrm{r}_{\mathrm{ox}}\left(\left[\mathrm{O}_{2}\right]\right)$ is the oxygen consumption rate in function of oxygen concentration.

Initially, two assumptions were systematically made, namely, (1) the system is in steady state: $\mathrm{d}\left[\mathrm{O}_{2}\right] / \mathrm{dt}=0$, and (2) far from sample edges, diffusion is unidirectional:

$$
\frac{\partial\left[\mathrm{O}_{2}\right]}{\partial \mathrm{t}}=\mathrm{D} \frac{\partial^{2}\left[\mathrm{O}_{2}\right]}{\partial \mathrm{z}^{2}}-\mathrm{r}_{\mathrm{ox}}\left(\left[\mathrm{O}_{2}\right]\right)
$$

Until 2001, only the case of constant oxidation rate (e.g., also constant oxidation profile) was considered. The models differed by the expression of $\mathrm{r}_{\mathrm{ox}}\left(\left[\mathrm{O}_{2}\right]\right)$ $[1,11,21,27,29,45]$.

Let us recall that the kinetic analysis leads to defining two kinetic regimes: The oxygen excess regime and the oxygen lack regime, with a critical oxygen concentration $\left[\mathrm{O}_{2}\right]_{\mathrm{C}}$ separating both regimes. The shape of the oxidation thickness profile depends on the difference between this critical concentration and the equilibrium oxygen concentration $\left[\mathrm{O}_{2}\right]_{\mathrm{S}}$, linked to oxygen pressure $\mathrm{p}$ and oxygen solubility in the polymer:

$$
\left[\mathrm{O}_{2}\right]_{\mathrm{S}}=\mathrm{pS}
$$

where $\mathrm{S}$ is the solubility coefficient of $\mathrm{O}_{2}$ in the polymer.

Two cases can be distinguished (Fig. 8.8).

In the case where $\left[\mathrm{O}_{2}\right]_{\mathrm{S}}<\left[\mathrm{O}_{2}\right]_{\mathrm{C}}$, all the thickness layers are in oxygen-lack regime, and the oxidation rate and the oxidation conversion decrease continuously with the depth. In the case where $\left[\mathrm{O}_{2}\right]_{\mathrm{S}}>\left[\mathrm{O}_{2}\right]_{\mathrm{C}}$, all the superficial layers in 

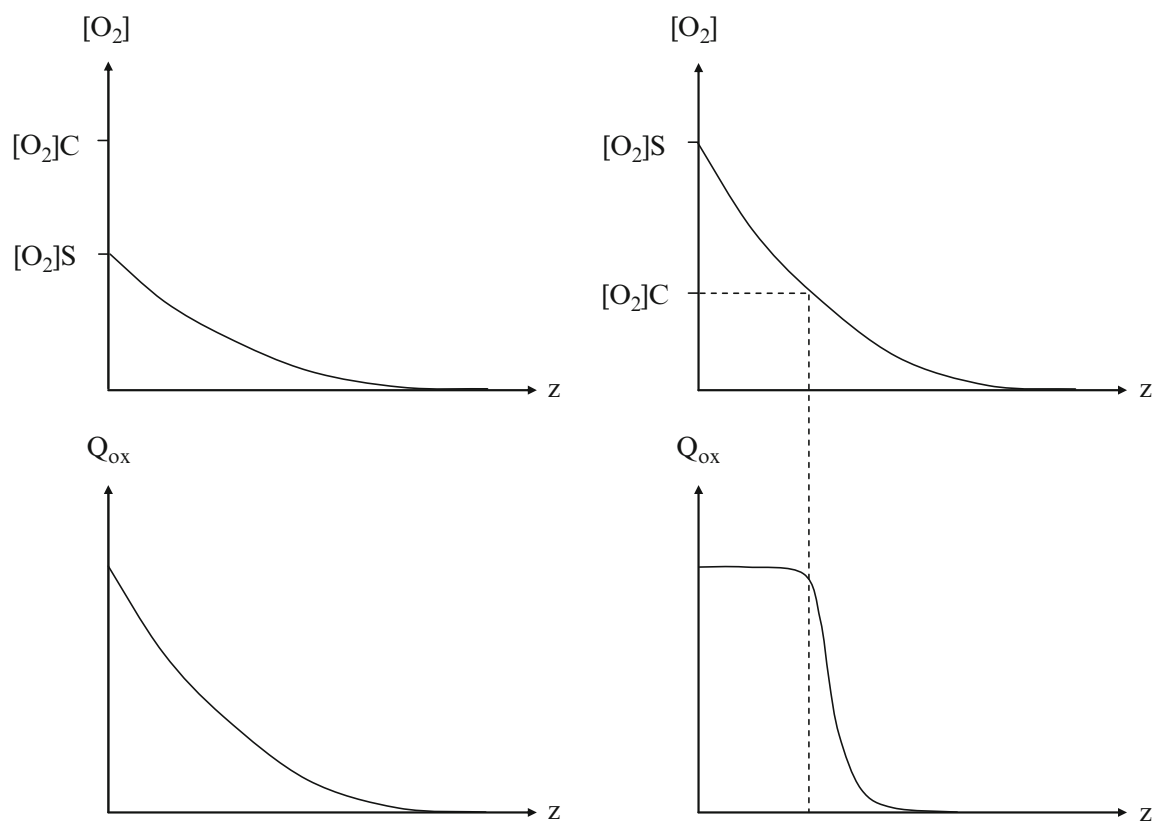

Fig. 8.8 Shape of oxygen concentration profile (above) and oxidation conversion profile (below). Polymer of type PP (left). Polymer of type PE (right)

which $\left[\mathrm{O}_{2}\right]>\left[\mathrm{O}_{2}\right]_{\mathrm{C}}$ are in oxygen-excess regime, in which the oxidation rate is independent of oxygen concentration. The oxidation profile displays, then, a plateau in its superficial layer.

From a simplified approach of the problem, Audouin et al. [3] showed that, in most cases, the thickness of the oxidized layer $\ell$ can be estimated with a simple scaling law:

$$
\ell \approx\left(\frac{\mathrm{D}}{\mathrm{K}}\right)^{1 / 2}
$$

where $\mathrm{D}$ is the oxygen diffusion coefficient and $\mathrm{K}$ is the pseudo first-order rate constant for oxygen consumption:

$$
\mathrm{K}=\frac{\mathrm{r}_{\mathrm{ox}}}{\left[\mathrm{O}_{2}\right]}
$$

This law is useful to predict the trends of variation of $\ell$, for instance, in the case of thermo-oxidation, the temperature effect. If $\mathrm{D}$ and $\mathrm{K}$ are assumed to obey (in a first approximation) Arrhenius law: 


$$
\mathrm{D}=\mathrm{D}_{0} \exp -\frac{\mathrm{E}_{\mathrm{D}}}{\mathrm{RT}} \quad \text { and } \quad \mathrm{K}=\mathrm{K}_{0} \exp -\frac{\mathrm{E}_{\mathrm{K}}}{\mathrm{RT}}
$$

then:

$$
\ell=\ell_{0} \exp -\frac{\mathrm{E}_{\ell}}{\mathrm{RT}}
$$

with $\ell_{0}=\left(\frac{\mathrm{D}_{0}}{\mathrm{~K}_{0}}\right)^{1 / 2}$ and $\mathrm{E}_{\mathrm{p}}=\frac{1}{2}\left(\mathrm{E}_{\mathrm{D}}-\mathrm{E}_{\mathrm{K}}\right)$.

Since, always, $E_{D}<E_{K}, \ell$ is expected to be a decreasing function of temperature as experimentally observed.

All the above quoted approaches have in common questionable assumptions, especially the "double steady state": one relative to the radical concentration $\left(\mathrm{d}\left[\mathrm{P}^{\circ}\right] /\right.$ $\mathrm{dt}+\mathrm{d}\left[\mathrm{PO}_{2}{ }^{\circ}\right] / \mathrm{dt}=0$ ) and the other relative to the diffusion-reaction balance $\left(\partial\left[\mathrm{O}_{2}\right] / \partial \mathrm{t}=0\right)$, which cannot describe the behavior during an autoaccelerated stage. All the simplifying assumptions were suppressed at the turn of the century $[40,41,13]$. The diffusion-reaction equation was integrated to the system of differential equations constituting the kinetic scheme, in the following form:

$$
\frac{\partial\left[\mathrm{O}_{2}\right]}{\partial \mathrm{t}}=\mathrm{D} \frac{\partial^{2}\left[\mathrm{O}_{2}\right]}{\partial \mathrm{z}^{2}}-\mathrm{k}_{2}\left[\mathrm{O}_{2}\right]\left[\mathrm{P}^{\circ}\right]+\mathrm{k}_{6}\left[\mathrm{PO}_{2}{ }^{\circ}\right]^{2}
$$

The system of equations is then solved in time (t) and space $(\mathrm{z})$ using the Rosenbrock's semi-implicit method dedicated to stiff problem of chemical kinetics. There is, henceforth, no limit (except a computing capacity one) for the complexity of the kinetic model, as recently shown in the cases of polyisoprene [17] or polybutadiene [19] elastomers, and in the case of chlorine dioxide effect on polyethylene [18] where three diffusion-reaction couplings, respectively relative to oxygen, antioxidant, and chlorine dioxide, are taken into account.

The specific case of composites involves several complications: anisotropy of diffusion, possible interfacial diffusion, modification of oxygen transport due to damage, etc. [14]. These aspects will be treated in another chapter.

\subsection{Consequences of Oxidation}

\subsubsection{Mass Variations}

Mass variations are usually expressed in fractions of the initial matrix mass $\mathrm{m}=\Delta \mathrm{w} / \mathrm{w}_{0}$. A part of mass loss is due to outgassing (sorbed water, residual monomers, and other molecular impurities). The rest of mass variation, which will be analyzed here, is due to oxidation and can be divided into two components: Mass gain due to oxygen grafting to the polymer and mass loss due to the 
evolution of volatile products, in which one can distinguish water coming from hydroperoxide decomposition and other volatile (organic) molecules coming from rearrangements of chain end radicals or chain scissions near to chain ends. It has been already established that the balance of oxygen grafting to the polymer is given by:

$$
-\frac{\mathrm{d}\left[\mathrm{O}_{2}\right]}{\mathrm{dt}}=\mathrm{k}_{2}\left[\mathrm{O}_{2}\right]\left[\mathrm{P}^{\circ}\right]-\mathrm{k}_{6}\left[\mathrm{PO}_{2}{ }^{\circ}\right]^{2}
$$

so that mass gain is given by:

$$
\frac{\mathrm{dm}^{+}}{\mathrm{dt}}=\frac{32}{\rho_{0}}\left(\mathrm{k}_{2}\left[\mathrm{O}_{2}\right]\left[\mathrm{P}^{\circ}\right]-\mathrm{k}_{6}\left[\mathrm{PO}_{2}{ }^{\circ}\right]^{2}\right)
$$

$\rho_{0}$ is the specific weight in $\mathrm{g} \mathrm{L}^{-1}$.

Mass loss can occur only in initiation or termination reactions. However, since the kinetic regime is always close to steady state, initiation and termination rates are almost equal and it is licit to consider that mass loss occurs only in the initiation step:

$$
\delta \mathrm{POOH} \rightarrow \alpha \mathrm{P}^{\circ}+\beta \mathrm{PO}_{2}^{\circ}+\mathrm{H}_{2} \mathrm{O}+v \mathrm{~V}
$$

where $\mathrm{V}$ is a "virtual volatile molecule" other than $\mathrm{H}_{2} \mathrm{O}$, of which the molar mass $\mathrm{M}_{\mathrm{V}}$ is the number average molar mass of the real volatile molecules and $v$ is the yield of volatiles, that is to say, the number of $\mathrm{V}$ molecules per initiation event. The, mass loss rate is given by

$$
\frac{\mathrm{dm}^{-}}{\mathrm{dt}}=-\frac{1}{\rho_{0}} \mathrm{k}_{1}[\mathrm{POOH}]^{\delta}\left(18+v \mathrm{M}_{\mathrm{V}}\right)
$$

Then, the whole mass variation is:

$$
\frac{\mathrm{dm}}{\mathrm{dt}}=\frac{\mathrm{dm}^{+}}{\mathrm{dt}}+\frac{\mathrm{dm}^{-}}{\mathrm{dt}}
$$

It is noteworthy that mass gain is mainly linked to propagation, whereas mass loss is exclusively linked to initiation or termination. As a consequence, mass gain must predominate in the case of long kinetic chain, whereas mass loss must predominate in the case of short kinetic chain. Two cases can then be distinguished (Fig. 8.9). In case (a), for instance, poly(bismaleimides) [12] or polypropylene [42], oxidation displays an induction period or, at least, an initial autoaccelerated period. The kinetic chain length decreases during exposure and mass gain, which increases during the induction period, is progressively supplanted by mass loss. In case (b), 
Fig. 8.9 The two kinds of gravimetric curves (see text)

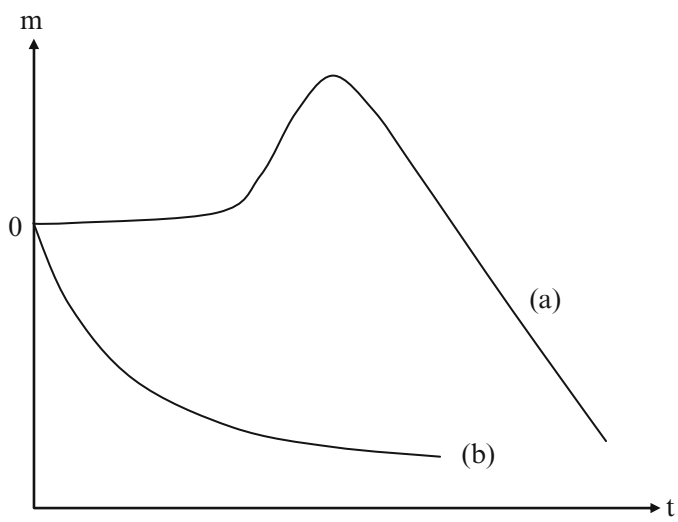

for instance, epoxies [12], hydroperoxides are very unstable, there is no induction period, the kinetic chain is initially short, and mass loss predominates as soon as exposure begins. The ability of the model to simulate the non-monotonic gravimetric behavior in the case, for instance, of poly(bismaleimides), constitutes a good argument in its favor. Indeed, mass loss must be calculated into elementary thickness layers and then, integrated in the whole sample thickness.

\subsubsection{Shrinkage}

In a given elementary layer, after the end of the induction period, the mass decreases due to volatile loss, and the density increases because light hydrogen atoms are replaced by heavier oxygen atoms. Density variations can be estimated from atomic composition variations using the following method: A constitutive repeat unit (CRU), representative of the whole polymer structure, is defined. Its molar mass is initially $\mathrm{M}_{0}$ and contains $\mathrm{N}_{0}$ atoms. One can define its average atomic mass:

$$
\mathrm{M}_{\mathrm{A} 0}=\frac{\mathrm{M}_{0}}{\mathrm{~N}_{0}}
$$

Making simple assumptions on oxidation mechanisms, one can determine the new CRU composition after a certain exposure time that leads to a new value of the average atomic mass: $\mathrm{M}_{\mathrm{A}}$. A correlation has been observed between polymer density and average atomic mass [35]:

$$
\rho=350+120 \mathrm{M}_{\mathrm{A}}
$$

$\rho$ is expressed in $\mathrm{kg} \mathrm{m}^{-3}$ and $\mathrm{M}_{\mathrm{A}}$ in $\mathrm{g} \mathrm{mol}^{-1}$. 
The parameters of this equation can be eventually refined for a given structural series. It is thus possible to predict the local density, at every time, in every location, from the kinetic model.

Then, the volume variation can be calculated from:

$$
\frac{\mathrm{dv}}{\mathrm{v}}=\frac{\mathrm{dm}}{\mathrm{m}}-\frac{\mathrm{d} \rho}{\rho}
$$

Since $\mathrm{m}$ decreases and $\rho$ increases, $\mathrm{v}$ decreases. In other words, oxidation induces shrinkage, and this latter induces a stress state. At more or less long term, the latter is responsible for a spontaneous superficial cracking of organic matrix composites [15].

\subsubsection{Glass Transition Temperature}

Except in the scarce cases where the composite matrix contains double bonds (for instance, diglycidyl ether of bisphenol A-methyltetrahydrophthalic anhydride networks [32]), oxidation induces essentially chain scission and the latter induces a decrease of the glass transition temperature $T_{\mathrm{g}}$. Chain scissions result from radical rearrangements and can occur only in initiation or termination events, so that the same reasoning as for mass variation can be made: It will be arbitrarily considered that chain scission occurs only in initiation:

$$
\frac{\mathrm{dS}}{\mathrm{dt}}=\frac{1}{\rho_{0}} \gamma_{1} \mathrm{k}_{1}[\mathrm{POOH}]^{\delta}
$$

where $\mathrm{S}$ is the number of moles of chain scission per mass unit.

In linear polymers, $S$ is linked to number and weight average molar masses $\mathrm{M}_{\mathrm{n}}$ and $\mathrm{M}_{\mathrm{W}}$ by:

$$
\mathrm{S}=\frac{1}{\mathrm{M}_{\mathrm{n}}}-\frac{1}{\mathrm{M}_{\mathrm{n} 0}} \quad \text { and } \quad \mathrm{S}=\frac{2}{\mathrm{M}_{\mathrm{W}}}-\frac{2}{\mathrm{M}_{\mathrm{W} 0}}
$$

In networks (for ideal or quasi-ideal networks at low conversions) by:

$$
\mathrm{S}=\frac{1}{\mathrm{M}_{\mathrm{e} 0}}-\frac{1}{\mathrm{M}_{\mathrm{e}}}
$$

where $\mathrm{M}_{\mathrm{e} 0}$ and $\mathrm{M}_{\mathrm{e}}$ are the respective molar masses of elastically active chains before and after aging. 
Thus, for a linear polymer:

$$
\mathbf{M}_{\mathrm{n}}=\left\{\mathbf{M}_{\mathrm{n} 0}^{-1}+\frac{\gamma_{1} \mathrm{k}_{1}}{\rho_{0}} \int_{0}^{\mathrm{t}}[\mathrm{POOH}]^{\delta} \mathrm{dt}\right\}^{-1}
$$

and for a tridimensional polymer:

$$
\mathbf{M}_{\mathrm{e}}=\left\{\mathrm{M}_{\mathrm{e} 0}^{-1}-\frac{\gamma_{1} \mathrm{k}_{1}}{\rho_{0}} \int_{0}^{\mathrm{t}}[\mathrm{POOH}]^{\delta} \mathrm{dt}\right\}^{-1}
$$

In linear polymers [26]:

$$
\mathrm{T}_{\mathrm{g}}=\mathrm{T}_{\mathrm{g} \infty}-\frac{\mathrm{K}_{\mathrm{FF}}}{\mathrm{M}_{\mathrm{n}}}
$$

where $\mathrm{T}_{\mathrm{g} \infty}$ and $\mathrm{K}_{\mathrm{FF}}$ are parameters specific to the polymer chemical structure (mainly chain dynamic stiffness), interrelated by [7]:

$$
\mathrm{K}_{\mathrm{FF}}=2.715 \times 10^{-3} \mathrm{~T}_{\mathrm{g} \infty}^{3}
$$

The Fox-Flory relationship can be thus transformed into:

$$
\mathrm{T}_{\mathrm{g} 0}-\mathrm{T}_{\mathrm{g}}=\mathrm{K}_{\mathrm{FF}} \mathrm{S}
$$

so that,

$$
\frac{\mathrm{dT}_{\mathrm{g}}}{\mathrm{dS}}=-\mathrm{K}_{\mathrm{FF}}
$$

The effect of chain scissions is an increasing function of the chain stiffness. Typically, $\mathrm{K}_{\mathrm{FF}}$ can be of the order of $10 \mathrm{~K} \mathrm{~kg} \mathrm{~mol}^{-1}$ for flexible chains (rubber) and of the order of $150-200 \mathrm{~K} \mathrm{~kg} \mathrm{~mol}^{-1}$ for stiff chains (aromatic polymers).

In tridimensional polymers [24]:

$$
\mathrm{T}_{\mathrm{g}}=\frac{\mathrm{T}_{\mathrm{gl}}}{1-2 \mathrm{Fv}}
$$

where $v=\mathrm{M}_{\mathrm{e}}^{-1}$ is the concentration of elastically active chains. $\mathrm{F}$ and $\mathrm{T}_{\mathrm{gl}}$, which are probably interrelated as $\mathrm{K}_{\mathrm{FF}}$ and $\mathrm{T}_{\mathrm{g} \infty}$ are, for example, $\mathrm{T}_{\mathrm{gl}}$ and $\mathrm{F}$ increase with the chain stiffness [6]. Thus,

$$
\frac{\mathrm{dT}_{\mathrm{g}}}{\mathrm{dS}}=-\frac{\mathrm{dT}_{\mathrm{g}}}{\mathrm{d} v}=-2 \mathrm{~F} \frac{\mathrm{T}_{\mathrm{g}}^{2}}{\mathrm{~T}_{\mathrm{gl}}}
$$


Here also, the effect of chain scissions is an increasing function of the initial $\mathrm{T}_{\mathrm{g}}$ value.

\subsubsection{Elastic Modulus in Rubbery State for Networks}

For networks in rubbery state (in the absence of post-cure or degradation processes during its measurement), the elastic modulus is linked to the concentration of elastically active chains:

$$
\mathrm{G}=\mathrm{RT} \rho \nu
$$

where $\mathrm{G}$ is the shear modulus.

Since the Poisson's ratio is close to 0.5 , the tensile modulus E is

$$
\mathrm{E}=3 \mathrm{RT} \rho v
$$

It becomes:

$$
\begin{gathered}
\frac{\mathrm{dG}}{\mathrm{dS}}=-\frac{\mathrm{dG}}{\mathrm{d} v}=-\mathrm{RT} \rho \text { and } \frac{\mathrm{dE}}{\mathrm{dS}}=-3 \mathrm{RT} \rho \\
\frac{\mathrm{dG}}{\mathrm{dt}}=\frac{\mathrm{dS}}{\mathrm{dt}} \frac{\mathrm{dG}}{\mathrm{dS}}=-\mathrm{RT} \rho \frac{\mathrm{dS}}{\mathrm{dt}}
\end{gathered}
$$

where $\mathrm{dS} / \mathrm{dt}$ is directly given by the kinetic model.

\subsubsection{Elastic Modulus in Glassy State}

Elastic modulus in glassy state depends mainly on the following factors:

- For amorphous polymers: cohesion and local mobility (responsible for sub-glass transitions)

- For semi-crystalline polymers: both above factors plus morphological parameters characterizing the crystalline phase

\subsubsection{In Linear Polymers}

Fracture properties fail before elastic properties have undergone significant changes. Semi-crystalline polymers can undergo chemicrystallization when they undergo degradation above $\mathrm{T}_{\mathrm{g}}$ of the amorphous phase [25]. 


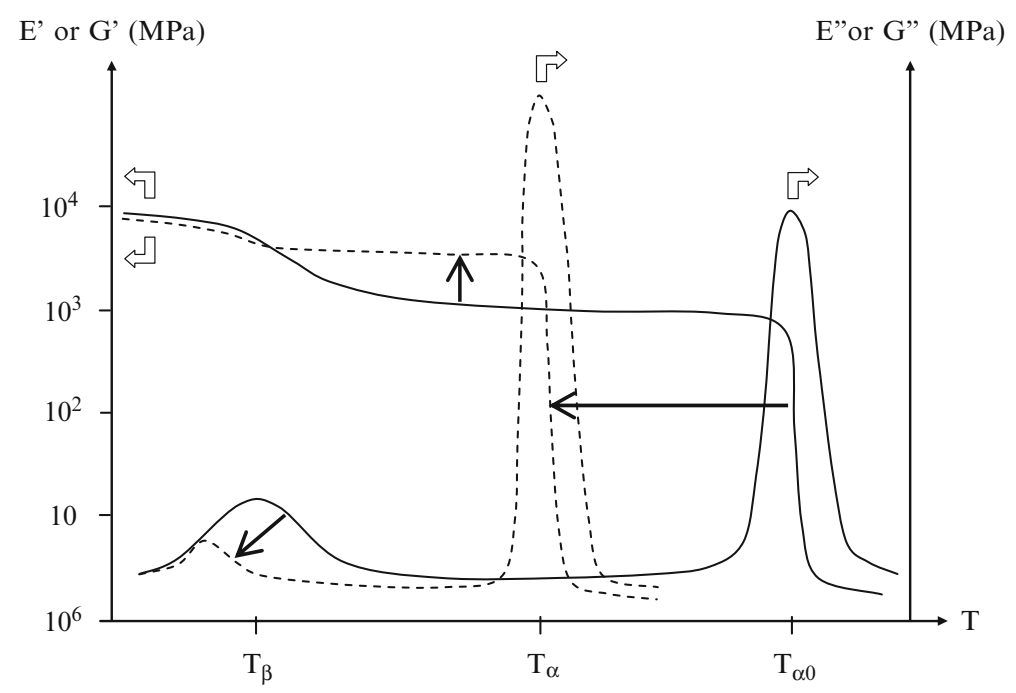

Fig. 8.10 Thermomechanical spectra of a network before (full lines) and after (dashed lines) degradation

\subsubsection{In Thermosets}

Two families can be distinguished:

1. Polymers having secondary transitions of low activity or overlapping glass transition (for instance, styrene cross-linked polyesters or vinylesters, and anhydride cured epoxies). In these cases, chain scissions have a negligible effect on modulus.

2. Polymers having secondary transitions of high activity and well separated from the glass transition (for instance, amine cross-linked epoxies). In this case, chain scissions induce an internal antiplasticization effect as illustrated by Dynamic Mechanical Analysis (Fig. 8.10).

Chain scission induces a decrease of the glass transition temperature, as expected, but also an increase of the modulus $\left(\mathrm{E}^{\prime}\right.$ or $\left.\mathrm{G}^{\prime}\right)$ at the glassy plateau between $T_{\beta}$ and $T_{\alpha}$. This phenomenon is called internal antiplasticization. It results from the inhibition of $\beta$ motions having the highest degree of cooperativity, and responsible for the high temperature side of the $\beta$ dissipation band. The bulk modulus $\mathrm{K}$ is not affected by the sub-glass transitions. In contrast, the shear $(\mathrm{G})$ and tensile (E) moduli above $\mathrm{T}_{\beta}$ depend on the activity of the $\beta$ transition. It can be written as

$$
\mathrm{G}=\mathrm{G}_{0}\left(1-\alpha \frac{\mathrm{T}}{\mathrm{T}_{\mathrm{g}}}\right)-\sum_{\mathrm{i}} \Delta \mathrm{G}_{\mathrm{i}}
$$



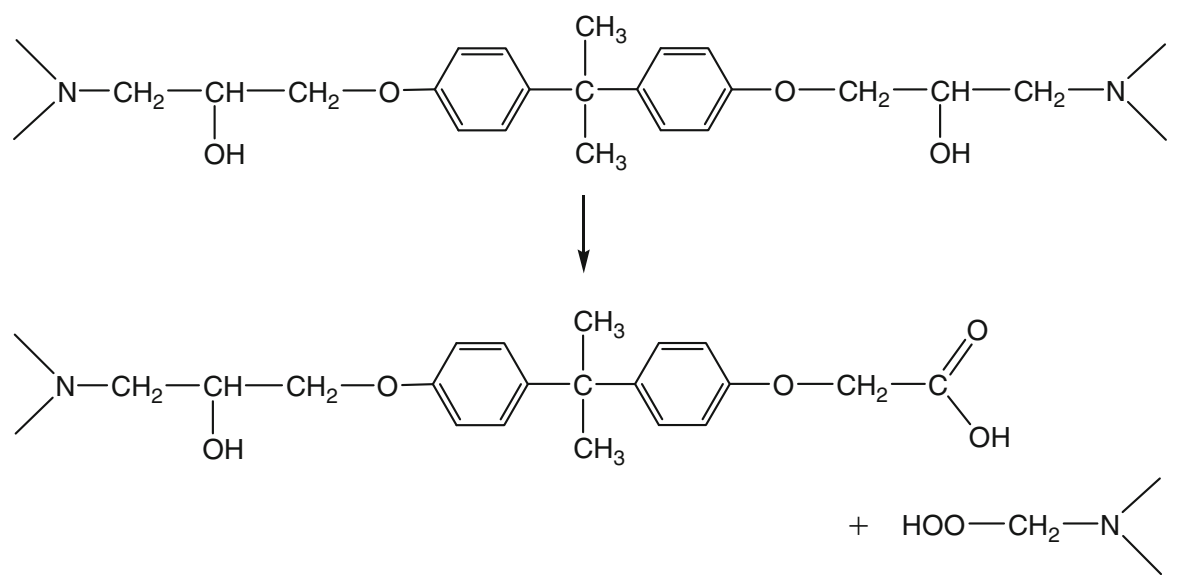

Fig. 8.11 Example of possible chain scission in an aromatic epoxide-amine network

where $\mathrm{G}_{0}$ is the shear modulus at $0 \mathrm{~K}$, which depends only on cohesive energy density, $\alpha \approx 0.3-0.5$ and $\Delta \mathrm{G}_{\mathrm{i}}$ is the modulus gap at the ith secondary transition below the temperature $\mathrm{T}$ [28].

Antiplasticization affects apparently only skeletal motions of the crankshaft type, so that the above relationship reduces to:

$$
\mathrm{G}=\mathrm{G}_{\mathrm{u}}-\Delta \mathrm{G}_{\beta}
$$

where $G_{u}$ is the unrelaxed modulus at the temperature under consideration and $\Delta \mathrm{G}_{\beta}$ is the modulus gap at the $\beta$ transition. Antiplasticization which results from chain scission, induces a decrease of $\Delta \mathrm{G}_{\beta}$ and, thus, an increase of G. Since $\mathrm{K}$ remains constant, this means that the tensile modulus increases:

$$
\mathrm{E}=\mathrm{E}_{\mathrm{u}}-\Delta \mathrm{E}_{\beta}
$$

and $\Delta \mathrm{E}_{\beta}$ decreases, whereas the Poisson's ratio decreases:

$$
\mu=\mu_{\mathrm{u}}+\Delta \mu_{\beta}
$$

where $\Delta \mu_{\mathrm{B}}$ decreases.

Quantitative relationships linking modulus changes to cross-link density are not yet established. A possible way to establish these relationships consists in studying model networks of well-defined structure [37]. In the case of aromatic epoxide-amine networks, chain scissions occur only in the isopropanol segment (Fig. 8.11).

It is noteworthy that un-degraded networks based on the same diepoxide and the same diamine, but with an epoxide excess, would contain dangling chains of almost the same structure as those created by oxidative degradation (Fig. 8.12). 
<smiles>CN(C)CC(O)COc1ccc(C(C)(C)c2ccc(OCC3CO3)cc2)cc1</smiles>

Fig. 8.12 Dangling chain in an epoxide-amine network containing an excess of epoxide

Let us consider the case of a diepoxide (of molar mass $\mathrm{M}_{\mathrm{E}}$ )-diamine (of molar mass $\mathrm{M}_{\mathrm{A}}$ ) network. For un-degraded networks differing by the amine/epoxide functional ratio (a), cross-link density and dangling chain concentration can be estimated as follows: Let us consider the constitutive repeat unit (CRU) based on two diepoxide molecules and a diamine molecule. In the case of epoxide excess, all the nitrogen atoms are fully reacted. For $(1-$ a) $<<1$, one can consider that all the dangling chains are isolated. The number of cross-link nodes is thus:

$$
\begin{aligned}
\mathrm{N}= & \text { Total number of nitrogen atoms }- \\
& \text { Number of nitrogen atoms connected to dangling chains }
\end{aligned}
$$

so that:

$$
\mathrm{N}=2 \mathrm{a}-(4-4 \mathrm{a})=6 \mathrm{a}-4
$$

and the cross-link density (node concentration) is thus,

$$
X=\frac{6 a-4}{2 M_{E}+a M_{A}}
$$

so that:

$$
v=\frac{3}{2} X=\frac{3}{2}\left(\frac{6 a-4}{2 M_{E}+a M_{A}}\right)
$$

whereas the concentration of dangling chains is:

$$
\mathrm{b}=\frac{4-4 \mathrm{a}}{2 \mathrm{M}_{\mathrm{E}}+\mathrm{aM}}
$$

Let us consider a stoechiometric network $(\mathrm{a}=1)$ which has undergone $\mathrm{S}$ chain scissions per mass unit. The concentration of elastically active chains is thus, at low conversions:

$$
v=v_{0}-3 S=\frac{2}{2 M_{E}+a M_{A}}-3 S
$$




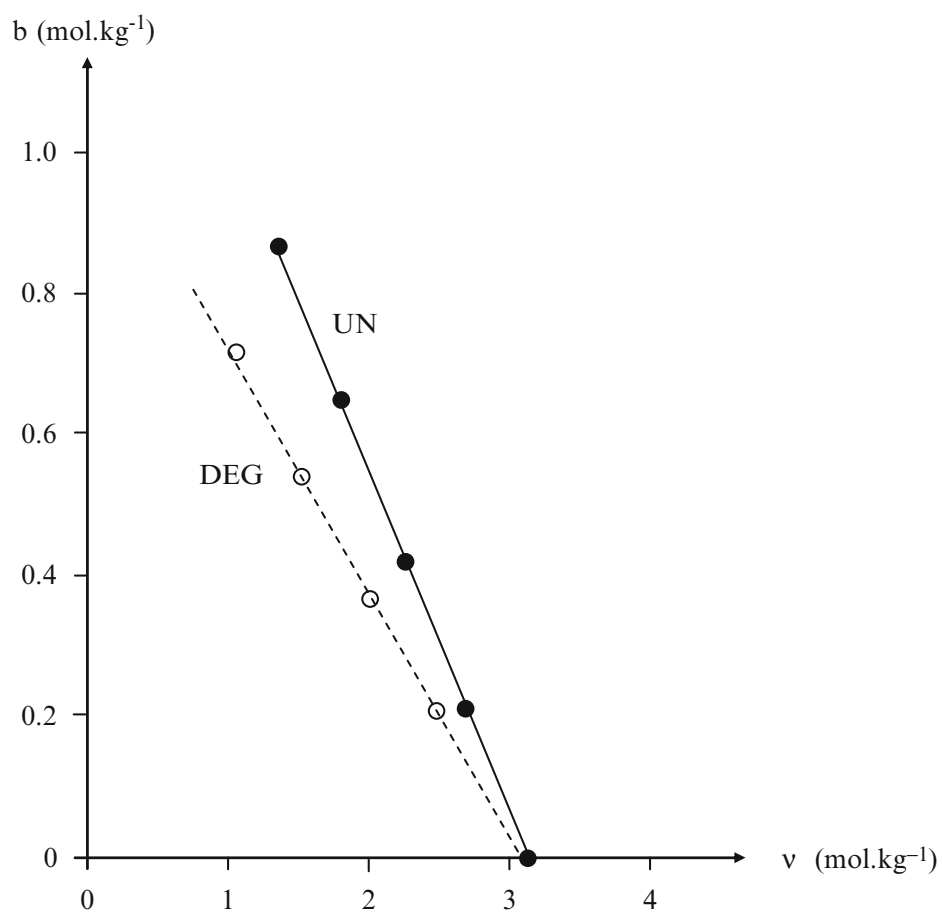

Fig. 8.13 Dangling chain concentration against cross-link density for un-degraded DGEBA-DDS networks containing an epoxide excess (UN) and for a stoichiometric DGEBA-DDS network undergoing chain scission (DEG)

and, since one dangling chain is created per chain scission:

$$
\mathrm{b} \approx \mathrm{S}
$$

The dangling chain concentration has been plotted against cross-link density for model networks differing by the amine/epoxide functional ratio $(\mathrm{a} / \mathrm{e} \leq 1)$ and for a degraded network, both structural series being based on the diglycidyl ether of bisphenol A-diamino dyphenylsulphone (DGEBA-DDS) system (Fig. 8.13).

The un-degraded networks contain more dangling chains, for a given cross-link density, than degraded ones, but the concentrations remain of the same order of magnitude, so that networks containing an excess of free epoxides are interesting model networks for degraded ones.

Modulus profiling by nano-indentation on oxidized samples shows that PMR-15 resin behaves as an epoxide-amine one, indicating thus the probable existence of an internal antiplasticization phenomenon [36]. 


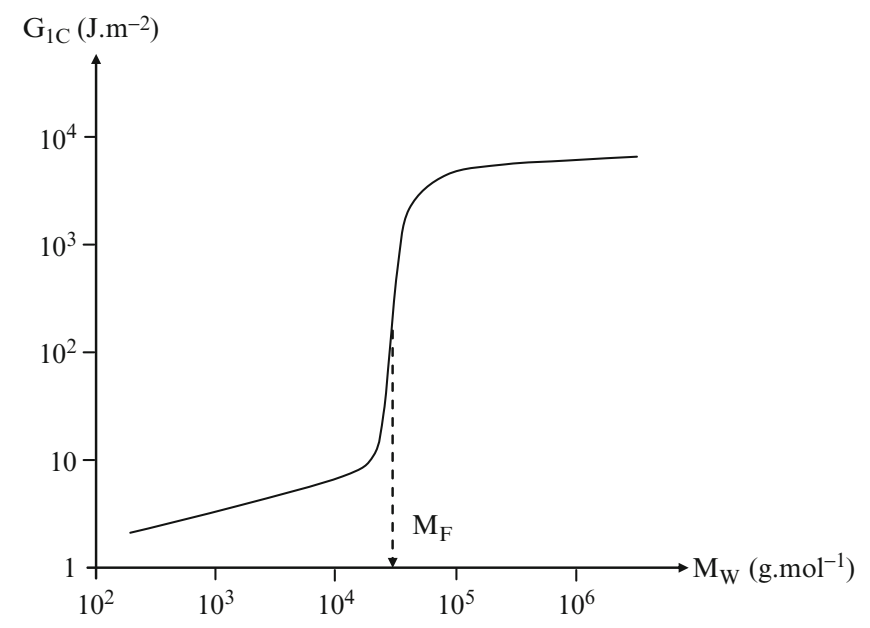

Fig. 8.14 Critical elastic energy release rate against weight average molar mass. General shape of the curve for linear polymers

\subsubsection{Toughness}

\subsubsection{Linear Polymers}

The toughness of linear polymers depends on molar mass according to a curve which always displays the shape of Fig. 8.14. This curve reveals the existence of two regimes of fracture: The "tough" regime where, typically, $\mathrm{G}_{1 \mathrm{C}}>1 \mathrm{~kJ} \mathrm{~m}^{-2}$, and the "brittle" regime where, typically, $\mathrm{G}_{1 \mathrm{C}} \leq 100 \mathrm{~kJ} \mathrm{~m}^{-2}$. A relatively sharp transition between both regimes is located at a critical molar mass $\mathrm{M}_{\mathrm{F}}$, which is always of the order of $10-100 \mathrm{~kg} \mathrm{~mol}^{-1}$.

For an industrial grade, the initial molar mass $\mathrm{M}_{\mathrm{W} 0}$ is always higher than $\mathrm{M}_{\mathrm{F}}$. Thus, during polymer oxidative degradation, the toughness will remain almost constant until the time where the molar mass value will reach $\mathrm{M}_{\mathrm{F}}$ and the behavior will suddenly turn to brittle regime (Fig. 8.15).

It is important to note that toughness varies almost in a discontinuous way while molar mass varies continuously. In initially brittle polymers (polystyrene, poly(methyl methacrylate), etc.), $\mathrm{G}_{1 \mathrm{C}}$ is the most pertinent quantity. In initially ductile polymers (polyolefins, polycarbonate, polysulphones, etc.), $\mathrm{G}_{1 \mathrm{C}}$ can be replaced by $\mathrm{J}_{1 \mathrm{C}}$ or simply, by the ultimate tensile elongation.

It has been tried to compare $\mathrm{M}_{\mathrm{F}}$ to the entanglement molar mass $\mathrm{M}_{\mathrm{e}}$. Two categories of polymers can be distinguished, depending on the ratio $\mathrm{q}=\mathrm{M}_{\mathrm{F}} / \mathrm{M}_{\mathrm{e}}$ :

1. For amorphous polymers and semi-crystalline polymers having their amorphous phase in glassy state (for instance, poly(ethylene terephthalate), poly(ether ether ketone), polyamides, etc.): $2 \leq \mathrm{q} \leq 10$. This means that embrittlement occurs 
Fig. 8.15 Shape of molar mass and toughness variations during aging

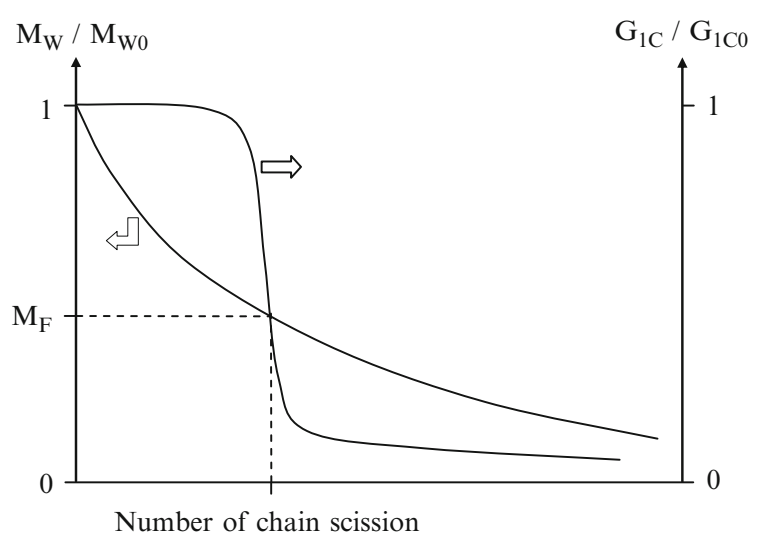

when the entanglement network has been significantly damaged. It is well known that chain drawing, responsible for plastic deformation, can occur only if the polymer is physically cross-linked by entanglements.

2. For semi-crystalline polymers having their amorphous phase in rubbery state (polyethylene, polypropylene, poly(tetrafluoroethylene), etc.), typically $q>25$. In these polymers, embrittlement results essentially from morphological changes (e.g., decrease of interlamellar amorphous phase thickness) resulting indirectly from chain scission [25].

\subsubsection{Thermosets}

Thermosets are generally brittle or semi-ductile, except eventually in the immediate vicinity of their glass transition. In ideal networks, the toughness depends mainly on the difference $\left(\mathrm{T}_{\mathrm{g}}-\mathrm{T}\right)$, $\mathrm{T}$ being the temperature at which fracture properties are measured. This means that, at a fixed measurement temperature $\mathrm{T}$, toughness is, roughly, a decreasing function of $\mathrm{T}_{\mathrm{g}}[35]$.

In a given structural series, $\mathrm{T}_{\mathrm{g}}$ is generally an increasing function of the crosslink density, so that toughness is found to be a decreasing function of the cross-link density, for example, for an ideal network, an increasing function of the molar mass $\mathrm{M}_{\mathrm{C}}$ of elastically active chains. It is tempting to apply these rules to degraded networks; however, in these, the number of elastically active chains decreases, but their length remains constant. As far as model networks are representative not only for elastic properties, but also for fracture properties, chain scission is expected to induce toughness decrease as illustrated in Fig. 8.16.

Unfortunately, very little is known on the quantitative relationships between structure and fracture properties in nonideal networks. 
Fig. 8.16 Critical elastic energy release rate against cross-link density for model networks DGEBA-DDS and DGEBA-ETHA [37]

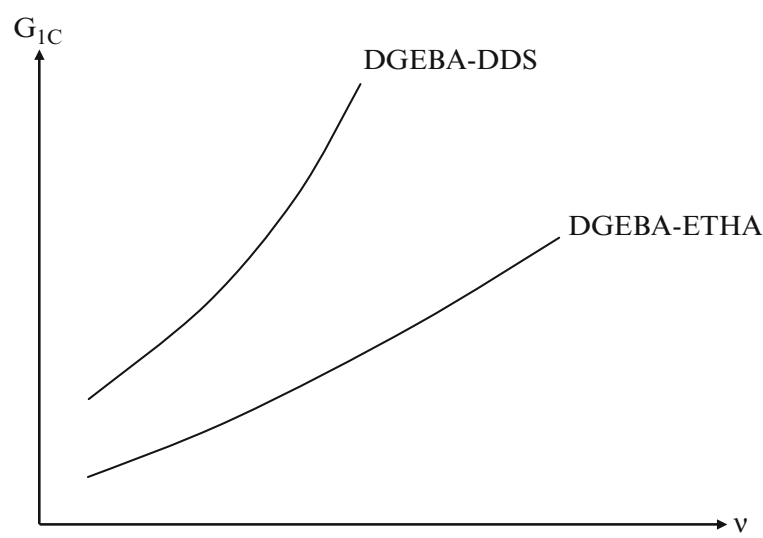

\subsection{Conclusion and Prospects}

The domain of polymer oxidation kinetics was characterized by a somewhat chaotic progression in the second half of the twentieth century. Among the possible reasons of its relative underdevelopment are, probably,

- A relative mistrust of chemical engineers about mathematical modeling

- The use and abuse of simplifying hypotheses to permit analytical resolution of kinetic schemes

The introduction, at the turn of the century, of numerical methods, allows suppressing of most of the undesired hypotheses and reconstructing kinetic curves from a mechanistic scheme that permit, first, a rigorous validation of the model by comparison to experimental curves and, second, the determination of certain elementary rate constants by an inverse approach.

For bulk polymer samples, it is now possible to accurately predict structural changes at all the pertinent structural scales:

- Local concentrations of oxygen containing groups (carbonyls, hydroxyls, hydroperoxides, etc.)

- Local quantities characterizing the macromolecular structure and directly linked to mechanical properties (molar masses, cross-linking densities, etc.)

- Depth distribution of the above characteristics at the micrometric scale

The ability of the model to predict at the same time complex kinetic behaviors (e.g., non-monotonic gravimetric curves) and distribution thickness profiles, independently of sample geometry, in a wide range of temperatures and oxygen pressures, illustrates well its power.

In the case of composites, many complications appear. The most important one, linked to the anisotropy of oxygen diffusion, is practically resolved now. The problem of interfacial degradation, in contrast, remains largely open. The problem of couplings between chemistry and diffusion with stress remains an almost virgin 
domain and would need, in future, significant research efforts. The key problem of the relationships between chemical changes and mechanical properties is that they are not totally elucidated and will also need, in the future, a noticeable volume of investigations. Numerical problems linked to tridimensional diffusion are now in the way to be solved, which will permit solving of heterogeneous kinetic schemes, for instance, due to chemical reactions between carbon fibers and reactive species participating in polymer oxidation.

\section{References}

1. Abdeljaoued, K.: Study of matrix thermal oxidation in carbon fibers-PMR-15 composites, PhD Thesis, ENSAM Paris, 1999.

2. Achimsky, L., Audouin, L., Verdu, J., Rychla, L., Rychly, J.: The effect of oxygen pressure on the rate of polypropylene oxidation determined by chemiluminescence, Europ. Polym. J. 35, 557-563 (1999).

3. Audouin, L., Langlois, V., Verdu, J., De Bruijn, J.C.M.: Role of oxygen diffusion in polymer aging. Kinetic and mechanistic aspects, J. Mater. Sci. 29, 569-583 (1994).

4. Audouin, L., Gueguen, V., Tcharkhtchi, A., Verdu, J.: Close-loop mechanistic schemes for hydrocarbon polymer oxidation, J. Polym. Sci.: Part A: Polym. Chem. 33, 921-927 (1995).

5. Audouin, L., Achimsky, L., Verdu, J.: Kinetic modelling of low temperature oxidation of hydrocarbon polymers, In: Halim Hamid S. (ed) Handbook of polymer degradation, $2^{\text {nd }}$ edition, chap. 16, pp. 727-763, Marcel Dekker, New York (2000).

6. Bellenger, V., Morel, E., Verdu, J.: Effect of structure on the glass transition temperature of amine crosslinked epoxies, J. Polym. Sci.: Part B: Polym. Phys. 25, 1219-1234 (1987).

7. Bicerano, J.: Prediction of polymer properties, $3^{\text {rd }}$ edition, chap. 6, p. 212, Marcel Dekker, New York (2002).

8. Bolland, J.L., Gee, G.: Kinetic studies in the chemistry of rubber and related materials. Parts II and III, Trans. Faraday Soc. 42, 236-252 (1946).

9. Bowles, K.J., Meyers, A.: Specimen geometry effects on graphite/PMR-15 composites during their thermo-oxidative aging, In: Proc of the $31^{\text {st }}$ International SAMPE Symposium and Exhibition, vol. 3, pp. 1285-1299. Covina, CA, US (1986).

10. Bowles, K.J., Nowak, G.: Thermo-oxidative stability studies of Celion 6000/PMR-15 unidirectional composites. PMR-15 and Celion 6000 fiber, J. Compos. Mater. 22(6), 966-985 (1988).

11. Colin, X.: Kinetic modelling of high thermomechanical performances polymer and composite materials, PhD Thesis, ENSAM Paris, 2000.

12. Colin, X., Marais, C., Verdu, J.: Kinetic modelling and simulation of gravimetric curves. Application to the oxidation of bismaleimide and epoxy resins, Polym. Degrad. Stab. 78(3), $545-553$ (2002).

13. Colin, X., Verdu, J.: Thermal ageing and lifetime prediction for organic matrix composites, Plastics Rubber Compos.: Macromol. Eng. 32(8/9), 349-356 (2003).

14. Colin, X., Marais, C., Verdu, J.: Kinetic modelling of the stabilizing effect of carbon fibers on thermal ageing of thermoset matrix composites, Compos. Sci. Technol. 65, 117-127 (2005a).

15. Colin, X., Mavel, A., Marais, C., Verdu, J.: Interaction between cracking and oxidation in organic matrix composites, J. Compos. Mater. 19(15), 1371-1389 (2005b).

16. Colin, X., Fayolle, B., Audouin, L., Verdu J.: The classical model for radical chain oxidation of hydrocarbon substrates initiated by bimolecular hydroperoxide decomposition, Intern. J. Chem. Kin. 38(11), 666-676 (2006). 
17. Colin, X., Audouin, L., Verdu, J.: Kinetic modelling of the thermal oxidation of polyisoprene elastomers. Parts I, II and III, Polym. Degrad. Stab. 92(5), 886-914 (2007).

18. Colin, X., Audouin, L., Verdu, J., Rozental-Evesque, M., Rabaud, B., Martin, F., Bourgine, F.: Aging of polyethylene pipes transporting drinking water disinfected by chlorine dioxide. Parts I and II, Polym. Eng. Sci., 49(7), 1429-1437 (2009) and 49(8), 1642-1652 (2009).

19. Coquillat, M., Verdu, J., Colin, X., Audouin, L., Nevière, R.: Thermal oxidation of polybutadiene. Parts II and III, Polym. Degrad. Stab. 92(7), 1334-1349 (2007).

20. Crews, L.K., McManus, H.L.: Modelling the high temperature degradation of graphite/epoxy, In: Proc. of the American Society for Composites, $12^{\text {th }}$ Technical Conference on Composite Materials, pp. 1123-1132. Detroit, MI, US (1997).

21. Cunliffe, A.V., Davis, A.: Photo-oxidation of thick polymer samples, Polym. Degrad. Stab. 4(1), 17-37 (1982).

22. Cunningham, R.A., McManus, H.L.: Coupled diffusion-reaction models for predicting the distribution of degradation in polymer matrix composites, In: Proc. of the ASME Aerospace Division, ASME International Mechanical Engineering Congress and Exposition, Symposium on Composite Materials, vol. 52, p. 353. Atlanta, GA, US (1996).

23. Denisov, E.T., Afanas'ev, I.B.: Oxidation and antioxidants in organic chemistry and biology, CRC Taylor and Francis, Boca Raton (2005).

24. Di Marzio, E.A.: On the second-(order transition of a rubber, J. Res. NBS: Section A: Phys. Chem. 68, 611-617 (1964).

25. Fayolle, B., Richaud, E., Colin, X., Verdu, J.: Review: Degradation-induced embrittlement in semi-crystalline polymers having their amorphous phase in rubbery state, J. Mater. Sci. 43, 6999-7012 (2008).

26. Fox, T.G., Flory, P.J.: Second-order transition temperatures and related properties of polystyrene. I. Influence of molecular weight, J. Appl. Phys. 21, 581-591 (1950).

27. Furneaux, G.C., Ledbury K.J., Davis, A.: Photo-oxidation of thick polymer samples. Part I: The variation of photo-oxidation with depth in naturally and artificially weathered low density polyethylene, Polym. Degrad. Stab. 3(6), 431-442 (1981).

28. Gilbert, D.G., Ashby, M.F., Beaumont, P.W.R.: Modulus maps for amorphous polymers, J. Mater. Sci. 21, 3194-3210 (1986).

29. Gillen, K.T., Wise, J., Clough, R.L.: General solution for the basic autoxidation scheme, Polym. Degrad. Stab. 47, 149-161 (1995).

30. Golike, R.C., Lasoski, S.W.: Kinetics of hydrolysis of polyethylene terephthalate films, J. Phys. Chem. 64, 895-898 (1960).

31. Korcek, S., Chenier, J.H.B., Howard, J.A., Ingold, K.U.: Absolute rate constants for hydrocarbon autoxidation. XXI: Activation energies for propagation and the correlation of propagation rate constants with carbon-hydrogen bond strengths, Can. J. Chem. 50, 2285-2297 (1972).

32. Le Huy, M., Bellenger, V., Paris, M., Verdu, J.: Thermal oxidation of anhydride cured epoxies. Part I, II and III, Polym. Degrad. Stab. 35, 77-86 (1992), 35, 171-179 (1992) and 41(2), 149-156 (1993).

33. Nam, J.D., Seferis, J.C.: Anisotropic thermo-oxidative stability of carbon fiber reinforced polymeric composites, SAMPE Quart. 24(1), 10-18 (1992).

34. Nelson, J.B.: Thermal aging of graphite/polyimide composites. In: O'Brien, T.K. (ed) Long term behaviour of composites, ASTM STP 813, pp. 206-221. American Society for Testing and Materials, Philadelphia, (1983).

35. Pascault, J.-P., Sautereau, H., Verdu, J., Williams, R.J.J.: Thermosetting Polymers. Marcel Dekker, New York (2002).

36. Putthanarat, S., Tandon, G.P., Schoeppner, G.A.: Influence of polishing time on thermooxidation characterization of isothermally aged PMR-15 resin, Polym. Degrad. Stab. 92, 2110-2120 (2007).

37. Rasoldier, N., Colin, X., Verdu, J., Bocquet, M., Olivier, L., Chocinski-Arnault, L., LafarieFrenot, M.-C.: Model systems for thermo-oxidized composites matrices, Composites: Part A: Applied Science and Manufacturing 39, 1522-1529 (2008). 
38. Reich, L., Stivala, S.S.: Autoxidation of hydrocarbons and polyolefins. Kinetics and mechanisms, Marcel Dekker, New York (1969).

39. Richaud, E., Colin, X., Fayolle, B., Verdu, J.: Induction period in the low temperature thermal oxidation of saturated hydrocarbons. Example of polyethylene, Intern. J. Chem. Kin. 40(12), 769-777 (2008).

40. Rincon-Rubio, L.M., Fayolle, B., Audouin, L., Verdu, J.: A general solution of closed-loop kinetic scheme for the thermal oxidation of polypropylene, Polym. Degrad. Stab. 74(1), 177-188 (2001).

41. Rincon-Rubio, L.M., Colin, X., Audouin, L., Verdu, J.: A theoretical model for the diffusionlimited thermal oxidation of elastomers at medium temperatures, Rubber Chem. Technol. 76(2), 460-482 (2003).

42. Rychly, J., Matisova-Rychla, L., Csomorova, K., Achimsky, L., Audouin, L., Tcharkhtchi, A., Verdu, J.: Kinetics of mass changes in oxidation of polypropylene, Polym. Degrad. Stab. 58, 269-274 (1997).

43. Salin, I.M., Seferis, J.C.: Anisotropic effects in thermogravimetry of polymeric composites, J. Polym. Sci.: Part B: Polym Phys. 31, 1019-1027 (1993).

44. Seferis, J.C.: Aging analyses of polymer composites through time-temperature equivalence. In: Reifsnider, K.L., Dillard, D.A., Cardon, A. (eds) Progress in durability analysis of composite systems, pp. 193-201, Balkema, Rotterdam (1998).

45. Seguchi, T., Hashimoto, S., Arakawa, K., Hayakawa, N., Kawakami, W., Kuriyama, I.: Radiation induced oxidative degradation of polymers. Part I: Oxidation region in polymeric films irradiated in oxygen under pressure, Radiat. Phys. Chem. 17(4), 195-201 (1981).

46. Semenov, N.M.: Chemical kinetics and chain reactions, Oxford University Press, London (1935).

47. Skontorp, A., Wong, M.S., Wang, S.S.: High temperature anisotropic thermal oxidation of carbon fiber reinforced polyimide composites. Theory and experiments, In: Street, K., Poursartip, A. (eds) Proc. of ICCM-10, $10^{\text {th }}$ International Conference on Composite Materials, vol. 4, pp. 375-382. Whistler, BC, Canada (1995).

48. Smith, Vale: Chimie et Industrie (Paris) 105(18), 1179 (1972).

49. Sommersall, A.C., Guillet, J.E.: Computer modelling studies of polymer photooxidation and stabilization. In: Klemchuk, P.P. (ed) Polymer stabilization and degradation, chap. 16, pp. 211-234, American Chemical Society, Washington, DC (1985).

50. Swern, D.: Organic peroxides, vols 1 and 2, Wiley-Interscience, New York (1971).

51. Tobolsky, A.V., Metz, D.J., Mesrobian, R.B.: Low temperature oxidation of hydrocarbons. The phenomenon of maximum rates, J. Amer. Chem. Soc. 72, 1942-1952 (1950). 